\title{
Clinical Utility of Cardiovascular Magnetic Resonance in Hypertrophic Cardiomyopathy
}

\author{
Martin S Maron
}

\begin{abstract}
Hypertrophic cardiomyopathy (HCM) is characterized by substantial genetic and phenotypic heterogeneity, leading to considerable diversity in clinical course including the most common cause of sudden death in young people and a determinant of heart failure symptoms in patients of any age. Traditionally, two-dimensional echocardiography has been the most reliable method for establishing a clinical diagnosis of HCM. However, cardiovascular magnetic resonance (CMR), with its high spatial resolution and tomographic imaging capability, has emerged as a technique particularly well suited to characterize the diverse phenotypic expression of this complex disease. For example, CMR is often superior to echocardiography for HCM diagnosis, by identifying areas of segmental hypertrophy (ie., anterolateral wall or apex) not reliably visualized by echocardiography (or underestimated in terms of extent). High-risk HCM patient subgroups identified with CMR include those with thinwalled scarred LV apical aneurysms (which prior to CMR imaging in HCM remained largely undetected), end-stage systolic dysfunction, and massive LV hypertrophy. CMR observations also suggest that the cardiomyopathic process in HCM is more diffuse than previously regarded, extending beyond the LV myocardium to include thickening of the right ventricular wall as well as substantial morphologic diversity with regard to papillary muscles and mitral valve. These findings have implications for management strategies in patients undergoing invasive septal reduction therapy. Among HCM family members, CMR has identified unique phenotypic markers of affected genetic status in the absence of LV hypertrophy including: myocardial crypts, elongated mitral valve leaflets and late gadolinium enhancement.

The unique capability of contrast-enhanced CMR with late gadolinium enhancement to identify myocardial fibrosis has raised the expectation that this may represent a novel marker, which may enhance risk stratification. At this time, late gadolinium enhancement appears to be an important determinant of adverse LV remodeling associated with systolic dysfunction. However, the predictive significance of LGE for sudden death is incompletely resolved and ultimately future large prospective studies may provide greater insights into this issue. These observations underscore an important role for CMR in the contemporary assessment of patients with HCM, providing important information impacting diagnosis and clinical management strategies.
\end{abstract}

Keywords: Hypertrophic cardiomyopathy, cardiovascular magnetic resonance, heart failure, sudden death, fibrosis

\section{Introduction}

Hypertrophic cardiomyopathy (HCM) is the most common genetic cardiomyopathy (prevalence of 1:500 in the general population) caused by mutations in genes encoding proteins of the cardiac sarcomere [1-5]. A clinical diagnosis of HCM is confirmed when unexplained increased LV wall thickness is imaged (range 13-60 $\mathrm{mm}$ with average $22 \mathrm{~mm}$ ) in the presence of a

Correspondence: mmaron@tuftsmedicalcenter.org Hypertrophic Cardiomyopathy Center, Division of Cardiology, Tufts Medical Center, Boston, MA nondilated LV chamber [1,3,6]. HCM is a global disease affecting many races and equally by gender $[7,8]$. Despite a diverse pattern of phenotypic expression and clinical course, HCM is compatible with normal life expectancy in the vast majority of patients [9-11]. However, a small but important subset of HCM patients remain at increased risk of adverse disease complications such as sudden death, progressive heart failure symptoms or stroke [1,12-15].

Genetics. HCM is caused by vast genetic heterogeneity with $>1,400$ mutations in 13 or more genes encoding

\section{Biomed Central}


contractile proteins of the cardiac sarcomere (or in sarcomere-associated proteins) with cardiac $\beta$-myosin heavy chain (MYH7) and cardiac myosin binding protein C (MYBPC3)(Figure 1) the two most common sarcomere mutant genes, each accounting for the majority of HCM [5,16-18]. Mutations responsible for HCM are transmitted in an autosomal dominant manner in which each offspring of an affecting family member has a $50 \%$ chance of inheriting the mutation. Nearly all patients who inherent a disease-causing mutation will demonstrate evidence of the disease with increased wall thickness by early adulthood. However, select mutations can demonstrate substantial variability in age-related penetrance, resulting in delayed expression of the phenotype into the third decade of life, or even beyond to mid-life [19].

Currently, clinic genetic testing can identify a sarcomere protein mutation in $50-60 \%$ of patients with a phenotype of HCM [17,20,21]. Therefore, the genetic basis of a substantial number of patients with phenotypic evidence of HCM remains uncertain [20]. However, in those HCM index patients in whom a mutation is identified, genetic testing can then provide the opportunity to identify relatives at-risk of developing disease $[17,20-22]$. For relatives identified as having a mutation but without left ventricular hypertrophy (ie., genotype positive/phenotype negative) it is likely that this patient will develop phenotypic evidence of disease at some point in there clinical course, prompting recommendations for continued imaging surveillance [23]. For those family members who do not carry the mutation there is no future risk of developing HCM and therefore no further testing is necessary $[17,21]$.

Genetic testing can also differentiate a number of uncommon systemic metabolic diseases, which can manifest a pattern of LV hypertrophy nearly identical to that of sarcomeric HCM but which have different treatment strategies. These diseases are due to mutations in encoding the $\gamma 2$ regulatory subunit of adenosine monophosphateactivated protein kinase (PRKAG2), lysosome associated membrane protein (LAMP2) and the recessive disorder Fabry disease caused by mutations in the gene $\alpha$-galactosidase (GLA) [17,21,24].

Currently, identifying HCM patients at risk for adverse disease-related events including sudden death cannot be predicted based on specific mutations [16,17,20,21,25]. As a result, management decisions such as ICD therapy for primary prevention cannot be made solely based on results derived from genetic testing $[21,26]$. Furthermore, the observation that disease expression among first-degree family members with HCM can be dramatically different as well as the fact that specific HCM phenotypes (ie., apical HCM, apical aneurysms, end-stage HCM, etc.) have diverse mutations associated with

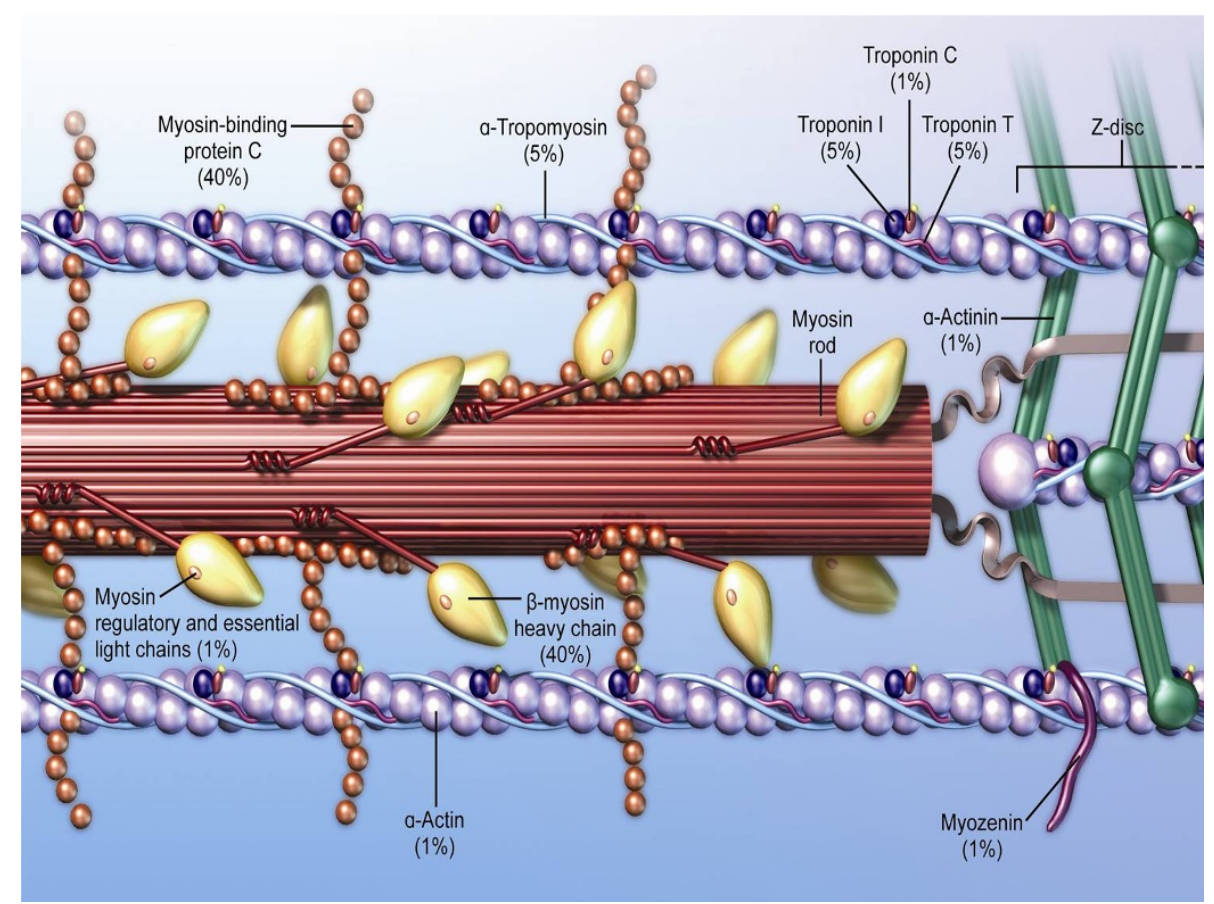

Figure 1 Cardiac sarcomere showing the location of known disease-causing genes for HCM. Adapted from Wheeler et al.[20] Not shown are genes previously linked to HCM, but with lesser degrees of evidence for disease causing: titin, vinculin, muscle LIM protein, telethonin, cardiac ankyrin repeat protein, calreticulin 3, calsequestrin 2, phospholamban, ryanodine receptor 2. 
them, suggest there is no clear relationship between mutation and phenotype [27]. The explanation for these observations may be due to a number of less wellunderstood factors, such as how modifier genes and environment also contribute to HCM disease expression [4].

\section{Cardiovascular magnetic resonance (CMR)}

Cardiovascular magnetic resonance (CMR) has recently emerged as an important imaging technique by offering a number of unique strengths which make it particularly well suited to provide detailed characterization of the HCM phenotype and therefore an important aid for diagnosis and potentially prognosis [28-34]. CMR can provide 3-dimensional tomographic imaging with high spatial and temporal resolution images of the heart, in any plane and without ionizing radiation (Figure 2) [30]. Contemporary functional cine CMR imaging sequences (ie., steady-state free precession) allow clear delineation of the endocardial and epicardial borders by producing sharp contrast between the interface of darkened myocardium and bright blood pool, which permit for precise wall thickness measurements in any location of the LV myocardium [34]. Furthermore, CMR provides truly tomographic imaging by acquiring a stack of short-axis images (with no interslice gap) with full ventricular coverage and therefore the opportunity to inspect the LV myocardium for limited, focal hypertrophy $[29,35]$. CMR images are not encumbered by the same limitations inherent in echocardiographic imaging, such as poor image quality related to thoracic or pulmonary parenchyma or inaccurate wall thickness measurements due to
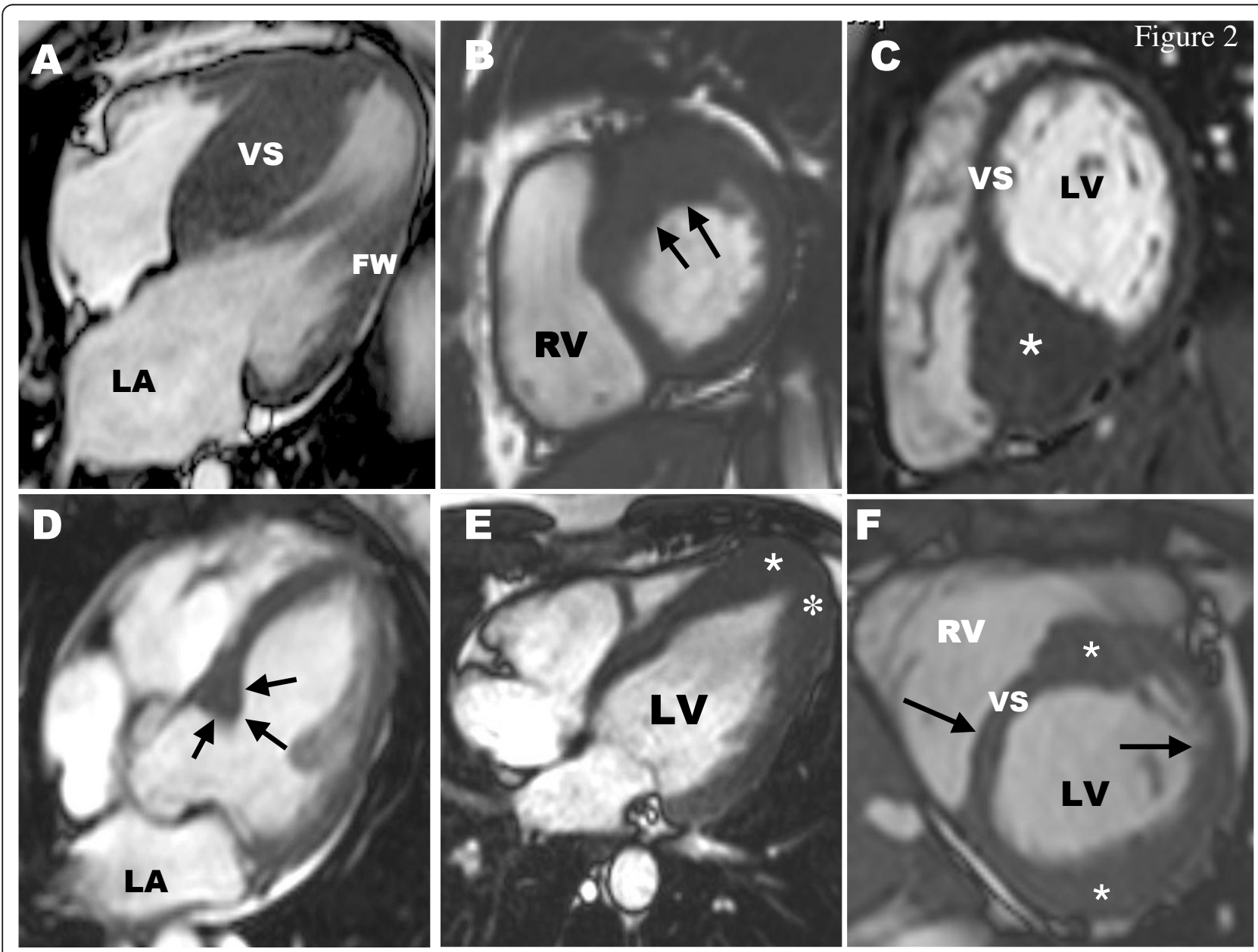

Figure $\mathbf{2}$ CMR end-diastolic images demonstrating diverse patterns of LVH in HCM. (A) involving ventricular septum (VS), but sparing the LV free wall (FW); (B) hypertrophy of the basal anterior free wall and a portion of the contiguous anterior septum, representing the most common area of LV wall thickening in $\mathrm{HCM}$; (C) massive hypertrophy (wall thickness, $33 \mathrm{~mm}$ ) limited to basal posterior ventricular septum (asterisk); (D) focal area sharply confined to basal anterior septum (arrows); (E) localized to LV apex (asterisks); (F) segmental LV hypertrophy of the basal anterior septum and anterolateral wall (asterisks), separated by regions of normal LV thickness (arrows). Adapted with permission, from Maron MS et al.[29] FW = free wall; $L A=$ left atrium; $L V=$ left ventricle; $R A$ = right atrium; $R V=$ right ventricle; $V S=$ ventricular septum. 
short-axis obliquity [30]. Lastly, myocardial fibrosis can be identified with contrast-enhanced CMR sequences after the intravenous injection of gadolinium images, which may select patients at increased risk of adverse disease consequences [36-39].

\section{CMR for Diagnosis}

Traditionally, two-dimensional echocardiography has been the primary imaging modality used for a clinical diagnosis of HCM by demonstrating an otherwise unexplained increase in LV wall thickness (avg., 21-22 mm) in the presence of a nondilated LV cavity $[1,40,41]$. However, over the last decade, several important observations have emerged related to the role of CMR in the diagnosis of HCM. First, when echocardiographic images are technically suboptimal and nondiagnostic, CMR has the distinct advantage of defining LV wall thickness measurements with high-resolution imaging $[33,41]$. Second, CMR has proved advantageous in identifying the presence and/or magnitude of LV hypertrophy, particularly when regions of increased wall thickness are completely (or predominantly) limited to only focal areas of the LV wall such as the anterior free wall, posterior septum and apex [29,35,42-45]. In one recent study, an important subset of patients with HCM were ultimately diagnosed with this disease only after LV hypertrophy was recognized in the anterolateral wall by CMR [35], suggesting this may be the most common area of the LV wall in which hypertrophy may be missed by echocardiography (Figure $3 \mathrm{a}$ and $3 \mathrm{~b})$. This

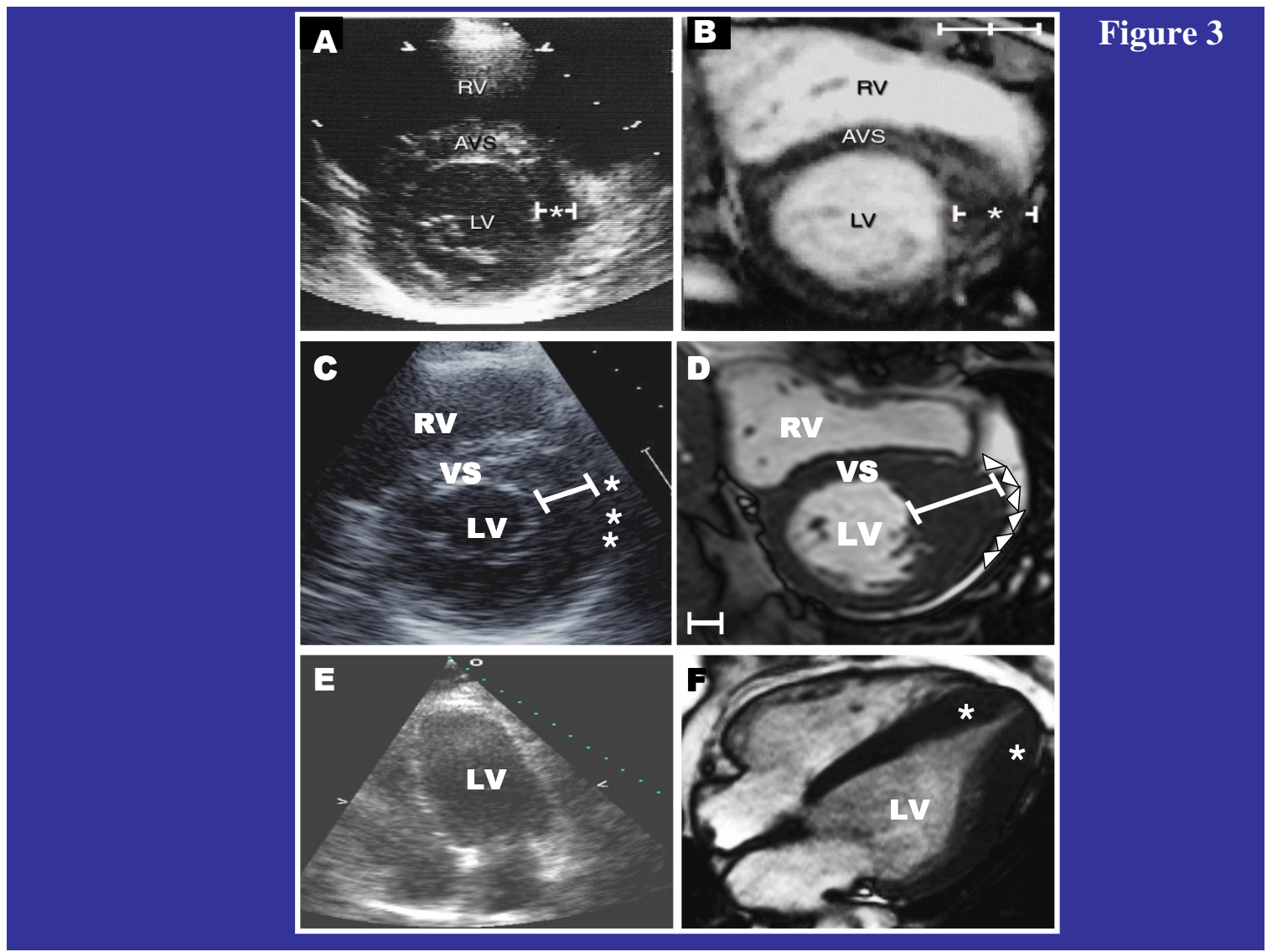

Figure 3 CMR can identify segmental LV hypertrophy that may not be reliably visualized by two-dimensional echocardiography. (A) normal 2-D echocardiogram in a patient with a family history of HCM; (B) this same patient then underwent CMR, which reveals an area of segmental hypertrophy in the anterolateral LV wall (asterisk) consistent with a diagnosis of HCM. Reproduced with permission of American Heart Association; from Rickers C et al.;[35] (C) two-dimensional echocardiographic end-diastolic basal short-axis view demonstrates a maximal LV wall thickness of $18 \mathrm{~mm}$ in the anterolateral free wall consistent with the diagnosis of HCM; (D) in the same patient, an end-diastolic short-axis CMR at the same level of LV shows a focal area of massive LV hypertrophy $(35 \mathrm{~mm})$ in the same region of the LV wall reported to be $18 \mathrm{~mm}$ by echocardiography. The finding of massive hypertrophy by CMR, characterized this patient as high risk, and prompted recommendation for ICD therapy for primary prevention of sudden death. Reproduced with permission, from Maron MS et al.:[42](E) echocardiography was considered non-diagnostic; (F) in the same patient, CMR clearly demonstrates segmental hypertrophy confined to the LV apex, consistent with a diagnosis of apical HCM. Reproduced with permission, from Moon et al.[43] LV = left ventricle; RV = right ventricle; VS = ventricular septum. 
observation can be explained due to the difficulty in differentiating the lateral epicardial border of the LV myocardium from the adjacent thoracic parenchyma in the short-axis orientation due to loss of spatial resolution in that portion of the imaging sector by echocardiography. For similar reasons, defining the epicardial border of the posterior septum in the area of insertion of the RV free wall can also be difficult with echocardiography [29]. Lastly, in some patients, thoracic and pulmonary parenchyma may limit the ability of echocardiocardiography to accurately define the endo or epicardial border of the apex, while CMR is not limited by such constraints (Figure $3 \mathrm{c}$ and $3 \mathrm{~d}$ ) [43-45]. These observations also support the wider use of CMR in screening family members [23].

\section{Phenotype Characterization \\ Pattern and distribution of LV hypertrophy}

The most common location for increased LV wall thickness in HCM patients is the confluence of the basal anterior septum with the contiguous anterior free wall (ie., one o'clock position in the LV short-axis image; Figure 2b) [29]. Hypertrophy involving both of these segments is present in close to 70\% of HCM patients and therefore this region of the LV constitutes the most frequent location for increased wall thickness in this disease. Due to the aforementioned limitations in accurately identifying the borders of these wall segments with lower spatial resolution echocardiography, this CMR observation in HCM differs from that of the impression of echocardiography in which the predominant area of hypertrophy was the basal anterior septum (ie., 12 o'clock position) [40]. In a population of HCM patients, the next most common region for increased wall thickness is the posterior septum at the mid-LV level (Figure 2c) [29].

The majority of HCM patients have diffuse hypertrophy involving more than $50 \%$ or greater of the LV myocardium (Figure 2a). Notably, a substantial minority of HCM patients have particularly focal or regional areas of increased wall thickness involving only one or two LV segments most commonly involving the basal anterior septum (Figure 2d) but also the anterolateral free wall, posterior septum and apex (Figure 2e) [29]. In addition, LV mass is normal in a substantial portion of HCM patients with limited, focal hypertrophy [46]. These CMR-based observations emphasize an important principle that even very limited hypertrophy (with normal LV mass), can be consistent with a clinical diagnosis of HCM $[29,46]$.

\section{Right ventricle}

Historically, a number of important limitations of 2-D echocardigraphy have made it difficult to accurately characterize the presence of RV morphologic abnormalities in patients with HCM. However, CMR has demonstrated a number of abnormalities including increased maximal RV wall thickness (ie., $\geq 8 \mathrm{~mm}$ ) in over one-third of HCM patients and in a substantial proportion of patients RV wall mass is also increased $[47,48]$. Areas of increased RV wall thickness are most commonly seen near the junction of the insertion of the RV wall into either the anterior or posterior septum (Figure 4a), although involvement of the entire RV does occur [47]. The totalities of these CMR-based observations expand on previous echocardiographic observations by demonstrating that the spectrum of phenotypic expression in HCM also includes morphologic abnormalities of the RV, although the prognostic significance of RV hypertrophy in HCM remains uncertain.

In addition to RV hypertrophy, CMR can also identify prominent RV muscle structures, such as the crista supraventricularis (Figure 5a). On the basal short-axis images this RV muscle structure is frequently situate adjacent to the ventricular septum and therefore incorrectly included in the measurement of maximal LV wall thickness (potentially resulting in an overestimation of wall thickness measurements; Figure 5b) [47]. However, with close visual inspection of the contiguous stack of short-axis cine CMR images, the crista muscle structure can be seen on certain short-axis slices to separate from the septum in diastole exposing the epicardial border of the ventricular septum allowing one to more easily delineate the epicardial border of ventricular septum (Figure 5b). In addition, HCM patients can develop subpulmonic RV obstruction due to substantial narrowing of the RV outflow tract from excessive hypertrophy of the RV free wall and ventricular septum. In those HCM patients considered for surgical relief of RV outflow tract obstruction, CMR can characterize the precise location and extent of hypertrophy in this region providing the surgeon information to help guide pre-operative surgical management.

\section{LV apical aneurysms}

HCM patients with thin-walled apical aneurysms associated with mid-ventricular hypertrophy represent an important subgroup of HCM patients who had been under diagnosed prior to the application of CMR to HCM (Figure 4b) $[33,49,50]$. This is largely due to the fact that small to moderate sized apical aneurysms may not be reliably detected with echocardiography for the same reasons that apical hypertrophy can also be missed $[43,44,50,51]$. Contrast-enhanced CMR has demonstrated that apical aneurysms are composed predominantly of fibrosis $[49,50]$. However, LGE often extends from the rim of the aneurysm into the septum and free wall with the junction of these areas representing a nidus for the generation of ventricular tachyarrhythmias [52]. Indeed, these morphologic changes related to the apex are likely what places these HCM patients at 

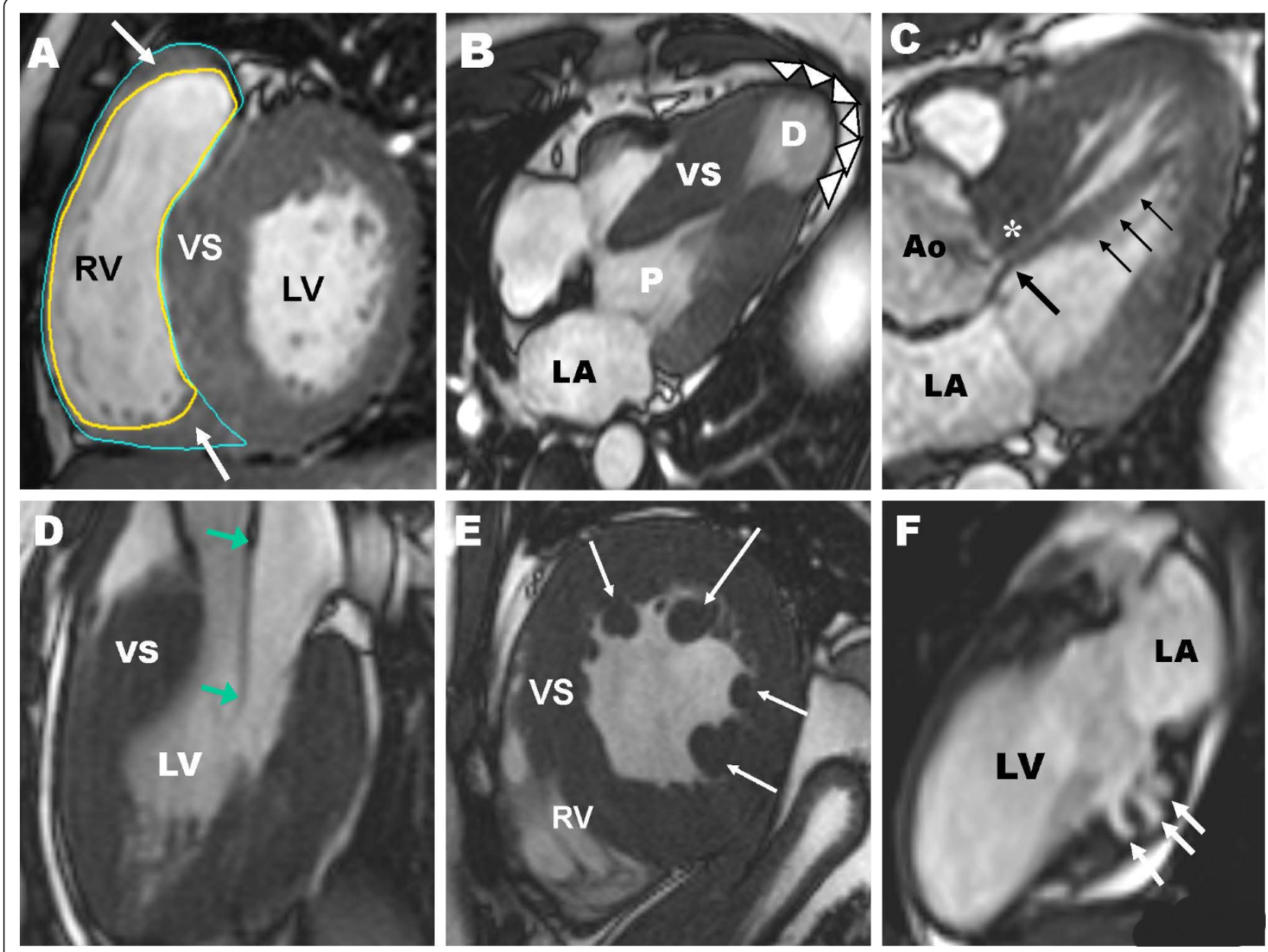

Figure 4 CMR end-diastolic images demonstrating diversity of the phenotypic expression within HCM. (A) increased wall thickness in the superior segment (thin arrow) and extreme hypertrophy of the inferior segment (thick arrow) of the RV wall; Reproduced with permission, from Maron MS et al.[29](B) medium-sized LV apical aneurysm (arrowheads) and maximal LV wall thickening at mid-ventricular level with muscular apposition of septum and LV free wall producing distinct proximal (P) and distal chambers; Reproduced with permission, from Maron MS et al. [50](C) anomalous insertion of papillary muscle (thin arrows) directly into the anterior leaflet of the mitral valve (thick arrow) (in the absence of chordae tendinae) producing obstruction to blood flow from the apposition of the papillary muscle and basal ventricular septum (asterisk); (D) extraordinarily long anterior mitral valve leaflet measuring $33 \mathrm{~mm}$; PML is of normal length (although not well visualized in this frame); Reproduced with permission, from Maron MS et al.[53](E) multiple accessory papillary muscles, 4 in number (arrows); Reproduced with permission from Harrigan C et al.[54](F) 7-year-old asymptomatic genotype positive/phenotype negative HCM girl with 3 deep myocardial crypts in the basal (posterior) inferior $L V$ free wall. $A o=$ aorta; $R V=$ right ventricle; $L A=$ left atrium; $L V=$ left ventricle; $V S=$ ventricular septum

increased risk of arrhythmic sudden death and stroke and thus represent a high-risk subgroup. Therefore, the diagnosis of patients with apical aneurysm directly impacts management recommendations for these patients, including consideration for ICD therapy and/or coumadin for stroke prophylaxis [49-51].

\section{Mitral Valve}

CMR has demonstrated that mitral valve abnormalities represent a primary phenotypic expression of this complex disease, suggesting that pathophysiologic pathways other than those related to the primary sarcomere disease-causing mutation may be important in contributing to aspects of HCM disease expression independent of
LV hypertrophy [53]. Mitral valve leaflets are increased in length in many HCM patients, including over onethird of patients with substantially elongated anterior $(\geq$ $30 \mathrm{~mm}$ )(Figure $4 \mathrm{~d}$ ) or posterior mitral leaflet lengths $(\geq$ $17 \mathrm{~mm}$ ) [53]. Leaflet lengths are elongated independent of a number of important HCM disease variables including: age, LV thickness or the presence of outflow tract obstruction. Therefore, these morphologic valvular abnormalities likely represent a primary phenotypic expression of this disease.

Elongated mitral valve leaflets also contribute substantially to the mechanism responsible for subaortic gradients, particularly in those select HCM patients in whom 


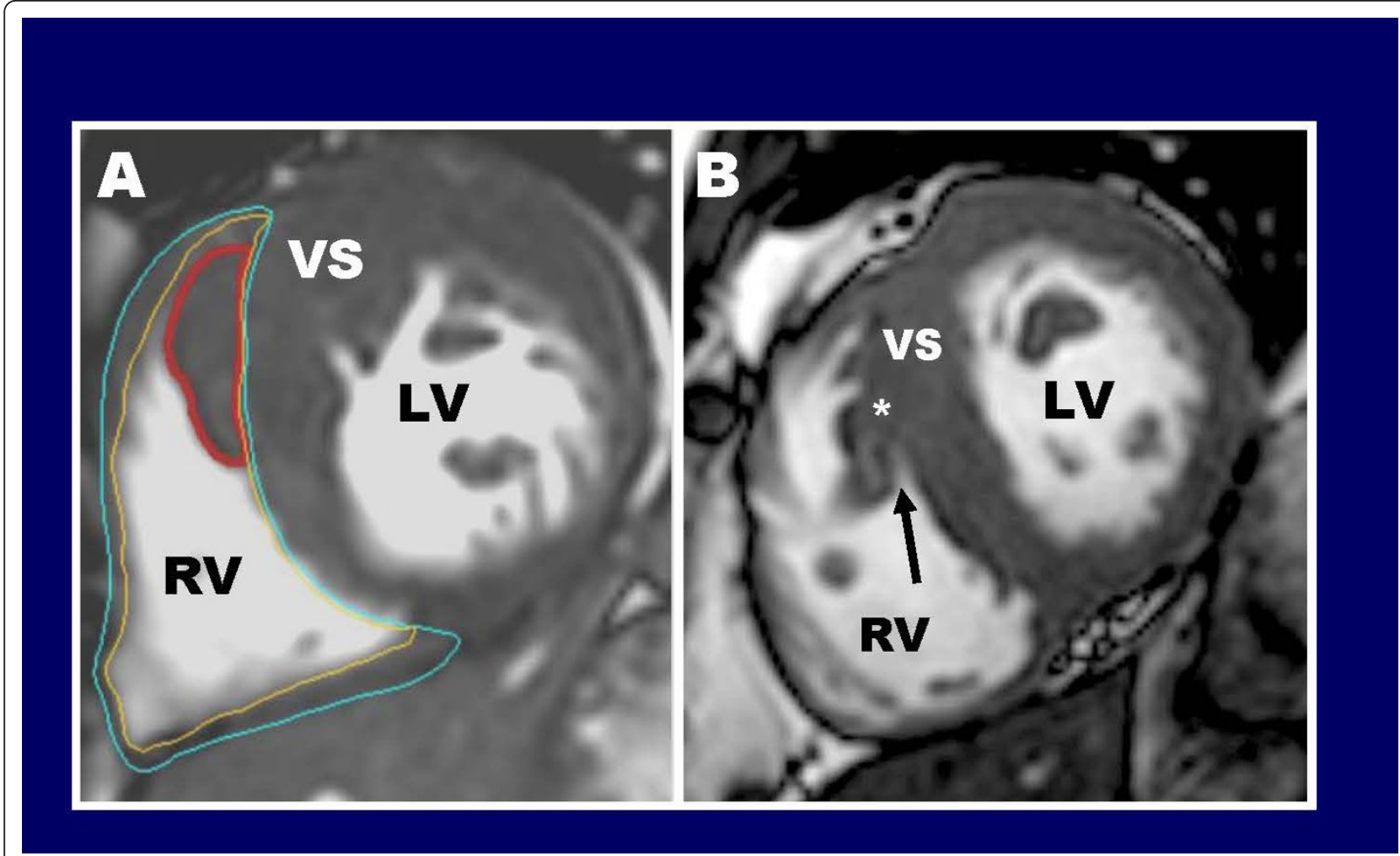

Figure 5 Right ventricular crista supraventricularis in HCM. When determining. where to measure the maximal LV wall thickness, it is important to be aware that HCM patients often have prominent and hypertrophied right ventricular muscular structures, the most common of which is the crista supraventricularis. In some HCM patients, the crista supraventricularis is not only significantly hypertrophied (panel $\mathbf{A}$, outlined in red) but not uncommonly inserts from its origin in the RV cavity to directly adjacent to the ventricular septum. As a result, this RV muscle structure may be inappropriately included in the measurement of septal thickness-resulting in an overestimation of the maximal LV wall thickness; Reproduced with permission, from Maron MS et al.[47]. In order to avoid including the crista supraventricularis as part of the septum, close inspection of the CMR short-axis cine images can help clarify this issue; (B) in a different HCM patient than panel A, the crista supraventicularis muscle is noted to move away from the septum toward the RV cavity with a small area of blood pool noted between the crista and septum (arrow), allowing for a more accurate delineation of the epicardial border of the septum (asterisk).

the mitral leaflet length exceeds 2 -fold the transverse dimension of the outflow tract at end-systole [53]. Therefore, substantially elongated mitral valve leaflets are an important determinant of LV outflow tract obstruction in some HCM patients, with implications for management strategies in this disease (See surgical myectomy section below).

\section{Papillary Muscles}

CMR has also expanded our appreciation of other morphologic abnormalities in patients with HCM in addition to those of the LV and RV wall, including the fact that abnormalities in papillary muscle morphology are common in HCM disease expression [54,55]. HCM patients frequently have an increase in the number of papillary muscles, including close to half of patients with 3 or 4 papillary muscles (Figure 4e) [54,55]. Hypertrophy of the papillary muscles is also common, including greater than half of HCM patients demonstrating a 2 -fold greater papillary muscle mass compared with than controls. Furthermore, there appears to be a subgroup of HCM patients with normal LV mass (but with localized increase in wall thickness), who nevertheless showed substantially hypertrophied papillary muscles with increased mass (20\% of patients) [54]. In such patients, the cardiomyopathic process either disproportional involved papillary muscles (compared to the LV wall), or preferentially affected the papillary muscles. Therefore, similar to the RV, LV papillary muscles appear be part of the cardiomyopathic process in HCM.

\section{Genotype Positive/Phenotype Negative HCM Patients}

The recent penetration of commercial genetic testing has resulted in the increased recognition of family member of HCM patients who carry a disease-causing sarcomere mutation but without LV hypertrophy (genotype positive/phenotype negative [G+/P-]) $[17,21,23]$. A variety of potential morphologic abnormalities may be present in G+/P- HCM patients and identified by CMR. 
The most recent of these has been the detection of myocardial crypts (ie., narrow, deep blood-filled invaginations within LV myocardium) localized predominantly to the basal posterior septum and LV free wall (Figure 4f) [56,57], although additional studies are needed to determine precisely how common crypts are in $\mathrm{G}+\mathrm{P}$ HCM patients compared to individuals without cardiovascular disease. In addition, elongated mitral valve leaflets [53], and LGE [58-60] may also be markers for gene positive status in HCM family members in the absence of LV hypertrophy. These CMR-based findings represent important clinical and morphologic abnormalities, which expand our current appreciation with respect to disease expression of $\mathrm{G}+\mathrm{P}$ - patients and provide evidence that even in the absence of hypertrophy hearts may be morphologically abnormal in this novel and emerging subgroup of HCM patients.

Furthermore, these observations support an expanded role for CMR in earlier diagnosis of relatives within HCM families [23,58]. For example, the identification of one of these morphologic abnormalities by CMR in a relative of an HCM patient in whom genetic testing cannot be performed due to cost or other considerations (or the mutation remains undefined even after testing), should prompt close surveillance with imaging studies to detect development of the phenotype. Also, in patients who can undergo genetic testing, identification of one of these morphologic abnormalities underscores the importance of pursuing genotyping to achieve definitive HCM diagnosis $[17,21,23]$.

\section{Role for CMR in Differential Diagnosis of LV hypertrophy Metabolic and Infiltrative Cardiomyopathies}

Although sarcomeric HCM accounts for the majority of unexplained left ventricular hypertrophy seen in adults, a number of other non-sarcomeric diseases can produce increased wall thickness of the myocardium as part of their phenotypic expression. Infiltrative cardiomyopathies such as cardiac amyloidosis, glyocogen/lysosomal storage diseases including Fabry's, Danons, and AMP kinase are considered to be the most common non-sarcomeric diseases in which cardiac phenotypic expression can mimic that of HCM (ie., "phenocopies") [61]. Fabry's disease is an X-linked storage disease in which mutations in the $\alpha$-galactosidase A gene lead to cellular accumulation of glycoshpingolipids in multiple organs, including the heart. Cardiac manifestations typically include left ventricular hypertrophy, valvular disease, atrial/ventricular arrhythmias and chest pain due to microvascular ischemia [61]. Although cardiac manifestations can occur early in life, they are generally not detected until the third or fourth decade but remain a major cause of death in patients with Fabry's [61]. Danon disease is another $\mathrm{X}$-linked lysosomal storage disease which can also result in systemic manifestations with associated cardiomyopathy. Clinical suspicion of Danon disease can be raised when young patients present with LV hypertrophy and a 12-lead electrocardiogram with pre-excitation pattern (ie., Wolf-ParkinsonWhite syndrome) [62]. Rapid clinical deterioration has been observed in patients with Danon disease (often occurring $<25$ years of age), leading commonly to heart failure death and even sudden cardiac death [62]. Although these diseases most often have non-cardiac signs and symptoms, in rare instances disease expression can be confined to only the heart [62].

An accurate diagnosis early in clinical presentation is critical, as treatment strategies and prognosis may differ for these diseases compared to HCM [24]. CMR may raise suspicion that a patient does not have HCM, when diagnosis remains uncertain after traditional imaging with two-dimensional echocardiography. For example, the demonstration with cine CMR of nearly identical increased wall thickness measurements in both the septum and LV free wall (ie., "concentric") combined with global subendocardial LGE on contrast-enhanced images is highly specific for cardiac amyloidosis [63]. A similar pattern of concentric wall thickening with LGE confined to the basal inferolateral wall has been frequently reported in Fabry disease [64]. Although CMR findings may suggest that the etiology of LV hypertrophy in an individual patient may be due to a metabolic/infiltrative cardiomyopathy rather than sarcomeric HCM, no pattern of LV wall thickening or LGE is pathogeumonic and therefore confirmatory diagnosis of these diseases ultimately requires the identification of a disease-causing mutation with genetic testing or typical histopathology on cardiac biopsy [17].

\section{LV noncompaction}

Furthermore, due to its super spatial resolution in imaging the distal LV myocardium, CMR may also help clarify (and even alter) diagnosis by demonstrating the presence of prominent trabeculations (ie., sinusoids) consistent with a diagnosis of LV noncompaction in patients initially diagnosed with apical HCM [65]. In this regard, the LV trabeculations associated with LV noncompaction may appear as apical hypertrophy when imaged with lower spatial resolution two-dimensional echocardiography, potentially resulting in a misdiagnosis of apical HCM in these patients. This also has important implications for management strategies as a diagnosis of LV noncompaction may have additional impact on treatment strategies (ie., coumadin) [66].

\section{Hypertensive Cardiomyopathy}

Differentiating HCM from wall thickening due to hypertension has historically represented a clinical challenge. Invariably, exposure to long-standing systemic hypertension will result in nearly identical wall thickening in the 
septum and LV lateral wall (ie., concentric hypertrophy). In addition, hypertensive cardiomyopathy is very rarely associated with resting LV outflow tract obstruction due to typical systolic anterior motion (SAM) with septal contact. Likewise, LV wall thickening in HCM is almost always asymmetric with resting outflow obstruction present in over one-third of patients.

In addition, a subset of HCM patients demonstrate non-contiguous patterns of LV wall thickening [29]. This morphologic pattern consists of hypertrophied segments separated by regions of non-hypertrophied myocardium, creating abrupt changes in wall thickness in adjacent portions of the wall and a "lumpy" hypertrophic pattern (Figure 2f). Such distribution of LV hypertrophy is most consistent with a genetically determined cardiomyopathic process (such as HCM) rather than those forms of hypertrophy secondary to pressure overload (such as in systemic hypertension), and recognition in selected patients could possibly contribute to resolution of the differential diagnosis between HCM and secondary hypertrophy from hypertension.

CMR can also be particularly helpful in detecting changes in serial measurements of LV wall thickness after treatment with antihypertensives, in which regression of hypertrophy would favor a diagnosis of hypertensive cardiomyopathy. In addition, when the distinction between these two disease entities still remains otherwise ambiguous in an individual patient, detection of HCM in family members who were previously undiagnosed or identification of a sarcomere mutation with genetic testing would provide additional evidence strongly favoring a clinical diagnosis of HCM.

\section{Athlete's Heart}

In addition, it may also be difficult to differentiate HCM from situations in which increased LV wall thickness results as a secondary response to intense athletic training. CMR can have a role in differentiating these conditions by identifying focal, limited hypertrophy not well visualized by echocardiography [67]. CMR is well-suited to accurately compare maximal LV wall thickness measurements before and after a period of systematic deconditioning. Patients in whom wall thickness regresses greater than $2 \mathrm{~mm}$ supports a diagnosis of athletes heart, while hypertrophy that remains unchanged suggests HCM [67]. At present, it does not appear that competitive athletes demonstrate LGE [68] and therefore the presence of LGE may also provide additional information to confirm diagnosis of HCM.

\section{Additional CMR Considerations}

\section{Hemodynamic Assessment of Outflow Obstruction}

Cine CMR can accurately identify the mechanism of subaortic obstruction in HCM with SAM-septal contact in both long-axis and basal short-axis images. Subaortic obstruction will result in high velocity blood flow in the outflow track area which can often be visualized as a systolic signal void jet (ie., black) in the region of SAMseptal contact [69]. In addition, a posteriorly directed signal void in the left atrium can also be seen and represents mitral regurgitation directed through the gap between the anterior and posterior leaflets.

In HCM patients with outflow tract obstruction, phase velocity flow-mapping sequences can be performed in order to determine the peak velocity of blood flow through the outflow tract as well as to quantify the amount of mitral regurgitation. However, only a small number of studies have assessed the accuracy of CMRderived LV outflow tract velocities compared to continuous-wave Doppler derived pressure gradients [69]. Therefore, it is not certain how well CMR-derived outflow tract velocities correspond to velocities obtained by the standard method of Doppler echocardiography and assessment with CMR can only be made under resting (basal) conditions. This represents a limitation for relying on CMR for gradient assessment as one-third of HCM patients have outflow obstruction only during provocation (ie., exercise). However, a recent study demonstrated that CMR planimetery of the LV outflow tract diameter could differentiate HCM patients with rest (or provokable) outflow tract obtstruction from nonobstructed [69]. Nevertheless, at the current time, clinical management decisions related to outflow obstruction should still likely be based on pressure gradients derived from Doppler echocardiography or hemodynamics obtained during coronary catheterization [41].

\section{Surgical septal myectomy}

HCM patients with LV outflow obstruction gradient $\geq$ $50 \mathrm{mmHg}$ at rest or with provocation, who have advanced heart failure refractory to medical therapy, are candidates for invasive septal reduction therapy to relieve obstruction and improve limiting symptoms $[3,70]$. Surgical myectomy is considered the "gold standard" for the treatment of outflow obstruction [3]. Contemporary surgical strategy requires a thoractomy followed by an aortotmy providing the surgeon direct visualization of the LV outflow tract morphology and the opportunity to resect between 3-12 grams of ventricular septum creating a basal septal trough, which widens the outflow diameter providing virtually complete elimination of outflow gradients in the vast majority of patients (and a substantially reduction in mitral regurgitation), resulting in a significant and long-lasting improvement in heart failure symptoms [71].

CMR has a role in pre-operative surgical myectomy planning in those HCM patients who are considered candidates for the operation by characterizing a number of important morphologic abnormalities related to outflow tract anatomy as well as the mitral valve and 
submitral apparatus [41,53-55]. For example, the identification of the pattern and distribution of wall thickening in the basal septum at the point of SAM-septal contact (particularly when these structures are not well visualized with echocardiography) can provide the surgeon an accurate estimate to the depth of the extended surgical resection of septal muscle necessary to achieve optimal relief of outflow obstruction [41].

CMR can identify additional morphologic abnormalities of the mitral valve and papillary muscles, which are important contributors to the mechanism responsible for subaortic gradients. Specifically, in those patients with substantially elongated mitral valve leaflets (Figure 4d) the mitral-septal contact point (and site of subaortic obstruction) can be displaced distal to its usual position. As a result, surgical strategy in this case may be altered to address this situation, by promoting extended muscular resection as well as the possibility of a combined approach of septal myectomy and mitral valve repair, with leaflet extension or plication, in order eliminate SAM of the mitral valve and absolute reduction of outflow gradients [53,72,73].

In addition, a number of other structural abnormalities of the submitral apparatus notable for proper surgical myectomy planning can be routinely identified by CMR. Apically displaced accessory anterolateral (Figure 4e) or a double bifid papillary muscle act to tether the plane of the mitral valve toward the ventricular septum facilitating the drag phenomenon of systolic anterior motion (SAM) and as a result are associated with a significantly higher likelihood of having outflow tract obstruction [54,55]. As a result, the surgeon, as part of an extended septal myectomy, often resects these papillary muscles in order to ensure a pristine hemodynamic result. In addition, anomalous insertion of the papillary muscle directly into the anterior leaflet of the mitral valve in the absence of chordae tendinae will result in mid-systolic apposition of the papillary muscle and ventricular septum resulting in midcavitary outflow obstruction (Figure 4c) and therefore often require distal resection of the basal septum as well as surgical revision of the abnormal papillary muscle [74].

\section{Alcohol septal ablation}

Alcohol septal ablation (ASA) is an alternative invasive septal reduction therapy in which 1-2 cc of alcohol are injected into an anatomically appropriate septal perforator artery supplying the basal septum (at the point of SAM-septal contact) creating a myocardial infarction resulting (ultimately) in septal thinning, widening of the LV outflow area and reduction of obstruction [75]. For HCM patients under consideration for ASA, there are currently no established CMR-based markers which identify HCM patients more likely to have an optimal hemodynamic result with ASA nor in identifying patients who are at risk for procedural complications such as complete heart block requiring permanent pacemaker implantation. CMR can precisely quantify the amount of tissue necrosis (average of $10 \%$ of LV mass) induced by ASA as well as identifying the relationship between the location of scarring and outflow tract morphology as well as accurately assessing regression of LV mass following the procedure [76,77].

\section{LVH and Risk Stratification LV hypertrophy}

Noninvasive imaging of LV wall thickness has proven to have a role in risk stratification with massive LV hypertrophy of $\geq 30 \mathrm{~mm}$ demonstrated by 2-D echocardiography anywhere in the LV chamber identifies those HCM patients at highest risk and potentially deserving of ICD therapy for primary prevention of sudden death $[26,41,78]$. Indeed, the presence of massive hypertrophy alone, in the absence of any additional risk markers, may be enough to recommend ICD therapy for primary prevention of sudden death [26]. Therefore, accurate assessment of maximal wall thickness is an essential part of the initial evaluation of all HCM patients. Previous observations have demonstrated that CMR can identify massive LV wall thickening ( $\geq 30 \mathrm{~mm}$ ), confined to the anterolateral free wall, which was substantially underestimated in magnitude by 2-dimensional echocardiography (Figure 3c and 3d) [42].

\section{Mass}

Due to the variable distribution of LV hypertrophy in regions of the $\mathrm{LV}$ chamber remote from maximal wall thickness, CMR-derived LV mass provides the most accurate assessment of the overall extent of LV hypertrophy in this disease. As a result, LV mass may represent a marker for adverse risk and would therefore seem to hold promise for aiding in risk stratification [46]. However, long-term prospective CMR studies are needed before establishing the precise relationship between LV mass and outcome in this disease.

\section{Significance and Clinical Implications of LGE}

Recently, considerable interest has emerged in using non-invasive in vivo detection of myocardial fibrosis as a prognostic marker in HCM [26,28,30,32]. Following the intravenous injection of gadolinium, contrast-enhanced CMR techniques can be applied to patients with HCM to detect areas of LGE, which can be planimetered and the amount quantified and expressed as a \% of the total LV mass. Depending on the selection of patients studied and which quantification technique used, between 50$80 \%$ of HCM patients have been reported to demonstrate LGE and when present occupying on average $10 \%$ of the overall LV myocardial volume (Figure 6) [36-39]. 


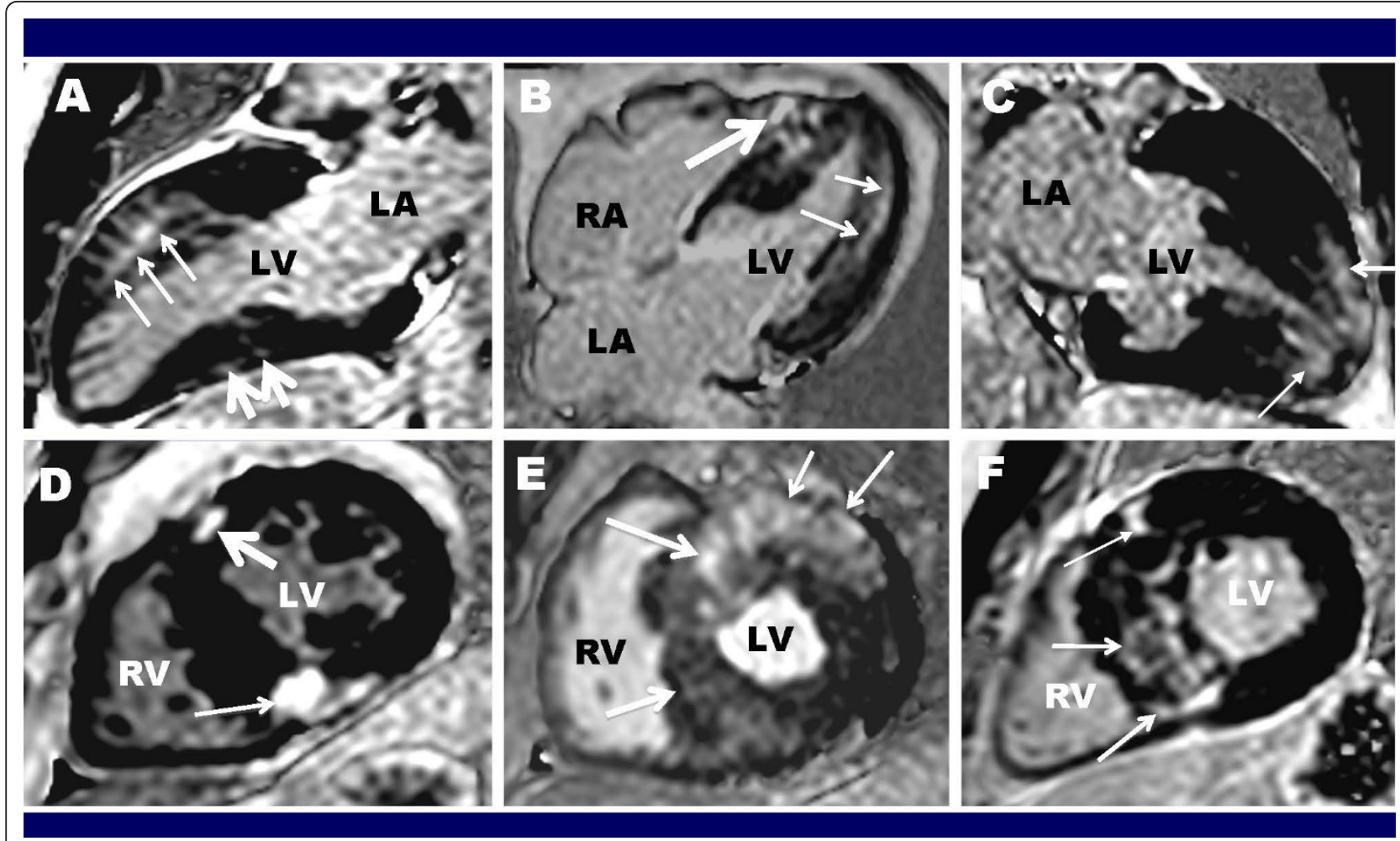

Figure 6 Contrast-enhanced CMR images in 6 different HCM patients demonstrating the diverse pattern and extent of late gadolinium enhancement in this disease. (A) extensive transmural LGE in the anterior wall (small arrows) with smaller focal area in the inferior wall (small arrows); (B) mid-myocardial LGE in the lateral wall (small arrows) and diffuse LGE in the ventricular septum which extends into the RV wall (large arrows) in a 26 year-old man with "end-stage" phase of HCM with an ejection fraction of 40\%; (C) LGE confined to the LV apex (arrows); (D) LGE localized to the insertion area of the RV wall into the anterior (large arrow) and posterior ventricular septum (small arrow); (E) transmural LGE involving the majority of the ventricular septum (large arrow) and lateral wall (small arrow). (F) Basal short-axis image with transmural LGE located predominantly in the ventricular septum (arrows). $R A=$ right atrium; RV = right ventricle; $L A=l$ left atrium; $L V=$ left ventricle

\section{Pathophysiology of LGE}

The precise pathophysiologic mechanism responsible for LGE in HCM currently remains uncertain. Nevertheless, observations derived from contemporary imaging and histologic studies provide support for the principle that LGE may derive from a pathophysiologic cascade in which repetitive bouts of microvascular ischemia result from structurally abnormal intramural coronary arteries (with impaired vasodilatory capacity) responsible, over a period of time, for myocardial ischemia-mediated myocyte death, ultimately triggering repair in the form of replacement fibrosis [79].

Indeed, there are a number of avenues of support for the principle that LGE probably constitutes (or largely represents) areas of myocardial replacement fibrosis. Studies in HCM patients with stress-CMR and PET have demonstrated myocardial blood flow to be substantially reduced in LV segments occupied by LGE and severely blunted in areas situated adjacent to LGE $[80,81]$. In ventricular septal tissue removed from HCM patients at the time of surgical myectomy, there is a strong association between the presence (and extent) of abnormal intramural coronary arteries (by histologic examination) and LGE (as determined from preoperative contrast-enhanced CMR studies) [82]. As well, blunted myocardial blood flow has also been shown to be an independent predictor of the end-stage phase of HCM (EF $<50 \%)$, [83] a phenotype associated with substantially amounts of myocardial fibrosis[84]. Indeed, the only reports correlating histologic evidence to CMR findings of LGE in HCM are a small number of case reports describing end-stage HCM patients in which LGE correlates to areas of fibrosis [85,86].

\section{Pattern and distribution of LGE}

Virtually any pattern, distribution and location of LGE can be observed in HCM, although LGE never corresponds to a coronary vascular distribution (Figure 6) $[37,87,88]$. LGE is most commonly located in both ventricular septum and free wall (over $30 \%$ of patients), but less commonly can be confined to the free wall, septum, apex, and the areas of right ventricular insertion into ventricular septum [37]. In addition, LGE can also occur 
in other structures outside of the LV, including RV wall $[47,48]$ and isolated to the papillary muscles [54], suggesting that a similar process of myocardial fibrosis which occurs in the LV can also occur (although much less frequently) in other areas of the heart.

Transmural extent of LGE in not uncommon, occurring in one-half of HCM patients [37]. A significant but modest relationship is present between hypertrophy and LGE. Patients with LGE have greater maximal LV wall thickness and LV mass index than patients without LGE $[37,87,88]$. On an individual patient basis, a relationship is also present between segmental LV wall thickness and LGE $[37,88]$.

\section{Adverse $L V$ remodeling}

One of the strongest and most consistent observations derived from a number of contemporary cross-sectional studies is the inverse relationship between ejection fraction and LGE in HCM. LGE extent is greatest in HCM patients with $E F<50 \%$. (ie., end-stage phase) while those with hyperdynamic LV systolic function have comparatively minimal LGE $[37,87,88]$. However, HCM patients with low-normal EF (50-65\%) show amounts of LGE that overlap those in the end-stage phase, and also demonstrate LV cavity dimensions that are more similar to the end-stage than patients with intact systolic function [89]. These observations would suggest some HCM patients with low-normal LV function are at risk of progressive fibrosis transitioning to a phase of more advanced LV remodeling associated with systolic dysfunction. However, due to the relatively recent introduction of CMR into cardiology practice, longitudinal follow-up studies characterizing the development and natural history of LGE in HCM are not yet available. Consequently, it is not possible at this time to determine if a threshold amount of LGE exists which identifies HCM patients at future risk of progressive remodelling. Nevertheless, these observations have potentially important clinical implications as HCM patients with systolic dysfunction represent a high risk subgroup at increased risk of sudden death and advanced heart failure symptoms prompting consideration for ICD therapy and alternative medical therapy e. g., ACE-inhibitors or aldosterone inhibitors to improve adverse LV remodelling [84]. Therefore, HCM patients identified with low-normal LV ejection fraction should undergo close clinical follow-up with serial imaging for prospective detection of changes in symptoms and LV structure.

\section{Heart failure symptoms with preserved EF}

At present, the precise impact of LGE on the development of heart failure symptoms is unresolved. A few studies have reported a weak but significant relationship between LGE and progressive heart failure symptoms/ death in HCM (and the risk proportional to the extent of LGE) $[37,38]$. However, in one such study, the clinical relevance of this relationship was driven predominantly by unplanned hospitalizations, a "soft" clinical end-point in HCM [38]. In addition, at this time it is not established that LGE provides additional information with respect to future risk of heart failure symptoms beyond the currently established predictors of symptom progression in this disease such as LV outflow tract obstruction [90].

\section{Sudden Death}

Despite considerable advances, risk stratification in HCM remains incomplete as some at-risk patients are not identified by the conventional risk factors suggesting a need to identify novel markers of susceptibility to sudden death risk $[12,26,91,92]$. Therefore, in this regard, there is substantial interest in exploring other modalities such as contrast-enhanced CMR. Indeed, based on recent cross-sectional studies, a strong association has been demonstrated between LGE and ventricular tachyarrhythmias on ambulatory 24-hour Holter ECG (Figure 7) [39,93-97]. Up to a 7-fold increased risk for potential lethal ventricular tachyarrythmias has been demonstrated among HCM patients with LGE compared to those without LGE [93]. These observations would suggest that LGE may represent an unstable arrythmogenic substrate responsible for ventricular tachyarrythmias in HCM.

Since nonsustained ventricular tachycardia is an independent risk factor for sudden death in this disease [98], the relationship between ambulatory ventricular tachyarrhythmia and LGE support the possibility that contrastenhanced CMR could represent a novel risk marker and thereby improve current risk stratification strategies by identifying HCM patients at increased risk of sudden death. In this regard, 4 prospective (short-term) outcome studies with relatively small number of HCM patients have been published that have demonstrated conflicting results regarding the relation between LGE and sudden death and/or appropriate therapy for ventricular tachycardia/fibrillation (table 1) [36-39]. When data from these studies were combined, LGE was more common in patients who experienced sudden death or an appropriate ICD discharge than those who did not resulting in a significant but weak relationship between the presence of LGE and risk for sudden death (table 1).

Therefore, available data do not strongly support LGE as a primary independent risk factor for sudden death in HCM [26]. As a result, recommendations for primary prevention ICDs should not be based solely on the presence of LGE in individual patients. Nevertheless, given the strong association of LGE and ambulatory ventricular arrhythmias, it is not unreasonable to give some weight to this finding as an arbitrator in reaching recommendations for prophylactic ICDs in selected 


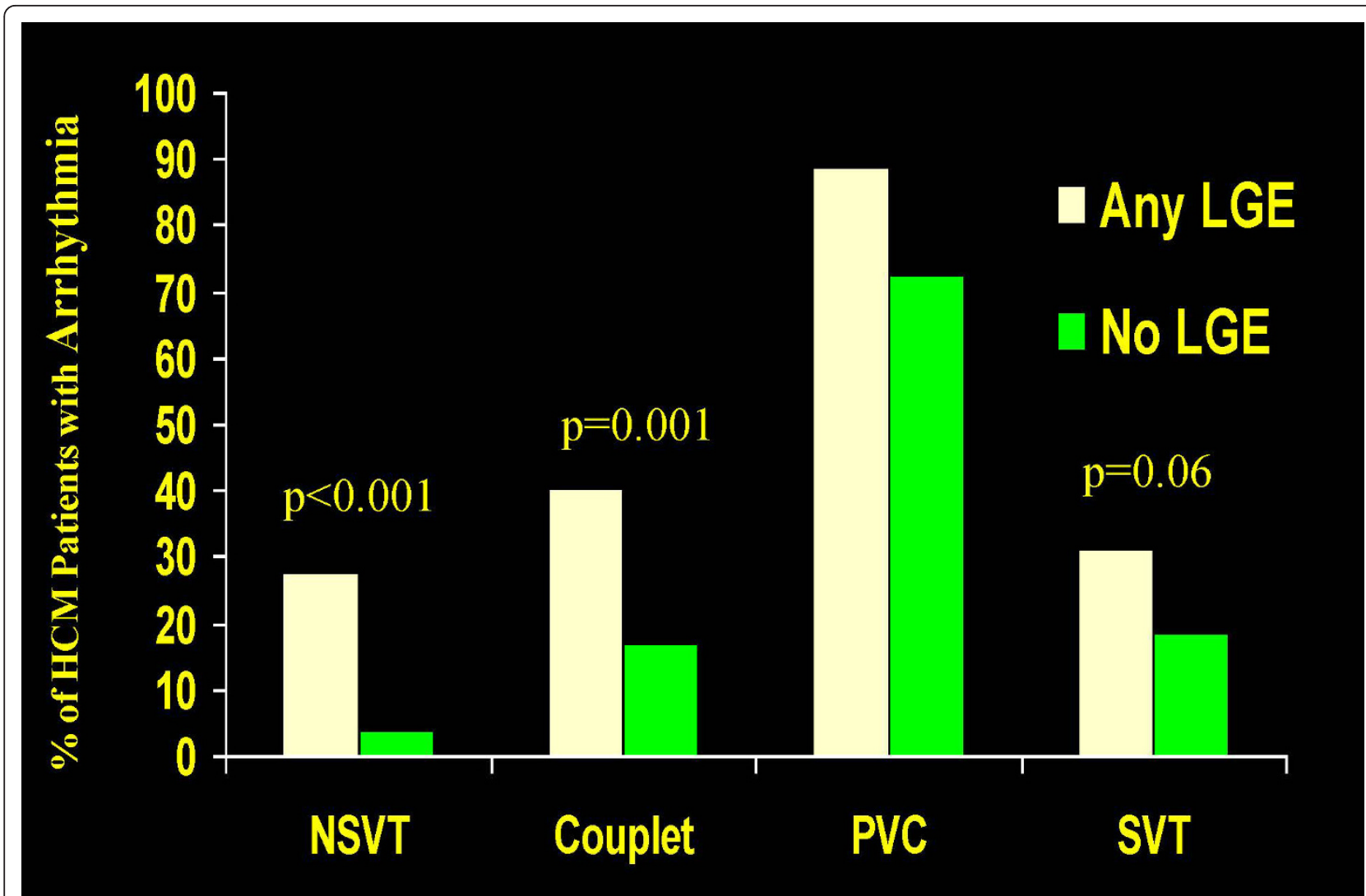

Figure 7 Prevalence of arrhythmia on 24-hour Holter ECG with respect to presence of late gadolinium enhancement in patients with HCM. Adapted with permission, from Adabag et al.[93]. ECG = electrocardiogram; HCM = hypertrophic cardiomyopathy; LGE = late gadolinium enhancement; NSVT = nonsustained ventricular tachycardia; PVC = premature ventricular contraction; SVT = supraventricular tachychardia

patients in whom other evidence of risk is ambiguous (Figure 8) [93].

The clinical significance of LGE is currently one of the most important and debated clinical questions in $\mathrm{HCM}$ $[28,99]$. Resolving this issue will require demonstrating that LGE is a clinically relevant marker of sudden death in large, prospectively selected cohorts with substantial number of patients followed over periods of time sufficient to ultimately provide the statistical robustness to establish the independent contribution of LGE to sudden death (in what is essentially a low-risk disease overall). In addition, it is imperative that future studies comparing LGE to outcome only employ established well-defined end-points clinically relevant to HCM, as well as compare the predictive value of LGE to the 5 established noninvasive risk markers currently used to identify patients at-risk.

Another point in establishing clinical relevance for contrast-enhanced CMR is the relationship of presence vs. extent of LGE with respect to outcome. The majority of follow-up contrast-enhanced CMR studies have reported only an association between the presence of

Table 1 Comparison of 4 short-term follow-up contrast-enhanced CMR studies in HCM

\begin{tabular}{|c|c|c|c|c|c|c|}
\hline Study & No. Patients & $\begin{array}{l}\text { LGE Quantification } \\
\text { Technique }\end{array}$ & Total SD Events & LGE Positive with SD & LGE Negative with SD & $p$-value \\
\hline Bruder et al 2010 & 220 & $\begin{array}{c}\geq 2 \mathrm{SD} \\
\text { Threshold }\end{array}$ & 11 & 10 & 1 & 0.1 \\
\hline O'Hanlon et al 2010 & 217 & FWHM & 4 & 3 & 1 & 1.0 \\
\hline Rubinshtein et al 2010 & 424 & Visual & 8 & 8 & 0 & 0.002 \\
\hline Maron et al 2008 & 202 & $\geq 6$ SD Threshold & 7 & 4 & 3 & 0.05 \\
\hline Overall & 1063 & ---二-ー- - & 30 & 25 & 5 & 0.04 \\
\hline
\end{tabular}

Abbreviations: FWHM = full width half maximum; LGE = late gadolinium enhancement; No. = number; SD = standard deviation 


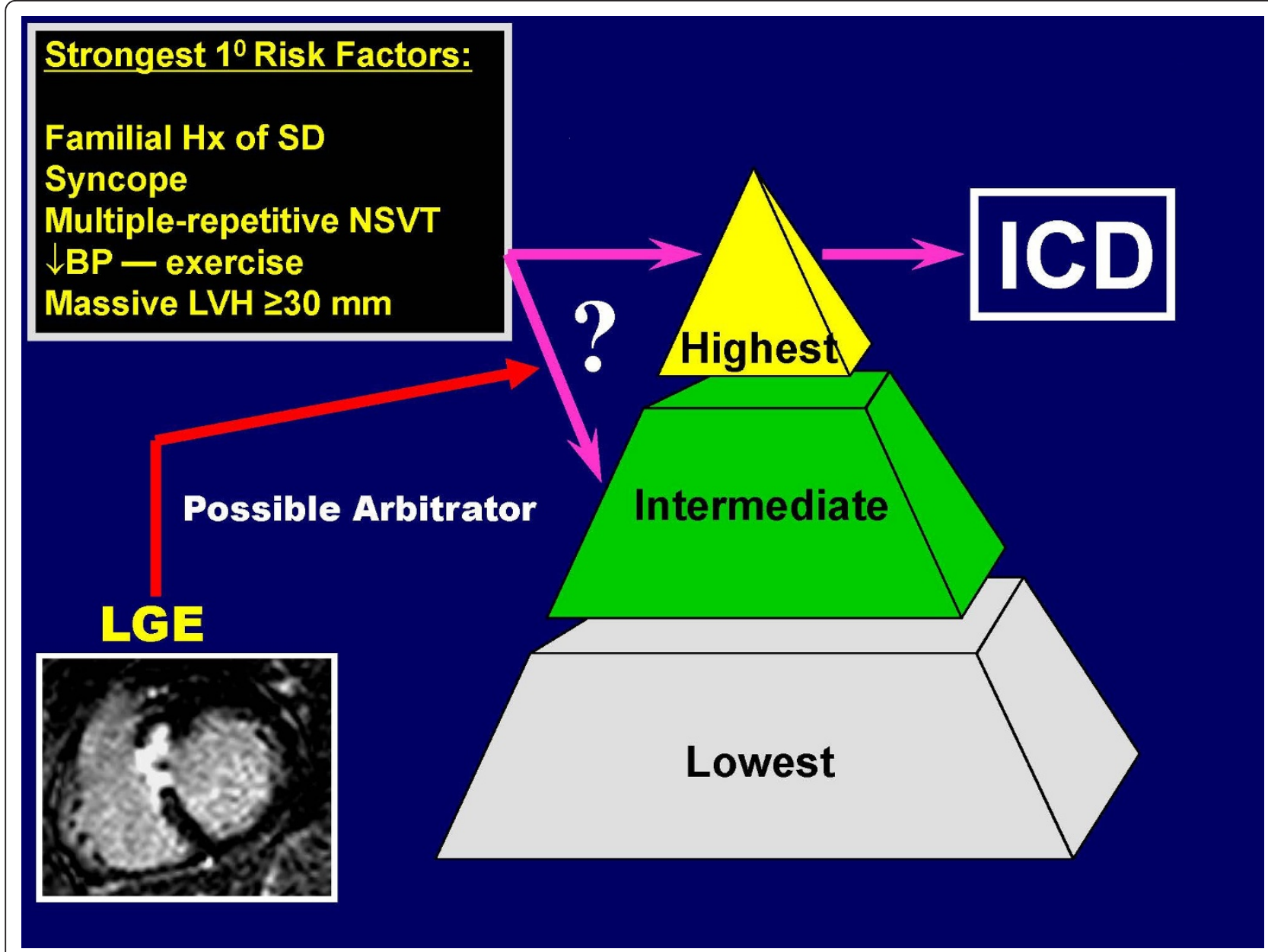

Figure 8 Role of CMR in Sudden Death Risk Stratification. Results of contrast-enhanced CMR with late gadolinium enhancement could be used as a potential arbitrator to arrive at a decision regarding ICD therapy for primary prevention of sudden death in HCM patients in whom risk still remains ambiguous after assessment with current conventional risk factors.

LGE and sudden death $[36,37,39]$. However, the reported prevalence of LGE is over $50 \%$ (up to $80 \%$ in one study)[97]. Therefore, even if some relationship can be derived between the presence of LGE and sudden death, LGE alone would not qualify as a practical risk marker as simply too many HCM patients would be identified for primary prevention ICDs. Therefore, for contrast-enhanced CMR to be a clinically useful tool for management decisions, it will likely be necessary to ultimately demonstrate that risk of adverse outcome is related to extent of LGE or when LGE is combined with the other currently established prognostic markers into a composite risk score for sudden death.

\section{LGE Disclaimers in HCM}

Does LGE always represent myocardial fibrosis in HCM?

Over the last several years, it has become increasingly common in the HCM literature and clinical arena to equate areas of LGE directly to myocardial fibrosis
$[28,82,85-88,93,95,100]$. This assumption is largely based on extrapolation from CMR-based animal models of myocardial fibrosis in which areas of fibrosis from the core infarct correlate to areas of LGE[101], as well as the association in HCM patients between areas of abnormal myocardial blood flow and hyperenhancement [79,81,102]. Yet in HCM, a number of obstacles continue to make it difficult to understand the precise histologic basis of LGE in this disease, including lack of a suitable HCM animal model and difficulty in obtaining post-mortem and explanted hearts for histopathologic examination close to the time of a prior clinical CMR examination. Indeed, the only correlative studies which directly relate CMR and histopathologic findings are derived from explanted end-stage HCM hearts $[85,86]$, making it difficult to extrapolate those findings to more typical HCM patients with normal preserved EF. However, these studies do show extensive amounts of fibrosis responsible for the adverse LV remodelling in this subgroup of HCM patients $[85,86]$. 
However, a number of CMR observations in HCM would suggest that, in fact, not all LGE may represent myocardial fibrosis in this disease. First, LGE in HCM is more commonly found in those LV segments which are the thickest with normal regional systolic function [37,87-89]. This observation is in direct opposition to that in patients with ischemic heart disease, in which LV segments with LGE are often thinned with associated wall motion abnormalities [103]. Second, extensive amounts of LGE can be present in asymptomatic HCM patients who have achieved advanced age (> 60 years) with normal systolic function and without adverse disease consequences such as potentially lethal arrhythmias, heart failure symptoms or adverse LV remodelling [37]. Furthermore, among end-stage HCM patients the amount of LGE often exceeds that observed in any other cardiovascular disease, including patients who have suffered large ST-segment elevation myocardial infarction suggesting that even within this subgroup of patients not all LGE maybe myocardial scar [84,89].

Therefore, based upon the totality of these observations it would be reasonable to consider that some LGE in HCM may represent histopathology which is not a result of myocardial scarring from replacement fibrosis. For instance, gadolinium may deposit within the diffuse interstitial collagen (matrix) compartment between normally aligned myofibrils or areas of perivascular fibrosis. Matrix collagen constitutes a greatly expanded extracellular tissue volume partially responsible for increased $\mathrm{LV}$ wall thickness, represents a primary morphologic feature of HCM, and provides an opportunity for gadolinium accumulation that may not reflect true replacement fibrosis. In addition, disorganized myocyte architecture will result in expanded areas of myocardial matrix where gadolinium could aggregate. Consistent with this point is the fact that one of the most common locations of focal LGE in HCM is at the insertion of RV wall into anterior or posterior ventricular septum $[37,39,87,88]$. Kuribayashi et al.[104] has shown in postmortem HCM hearts that this particular area of the LV chamber is characterized histologically by an expanded extracellular space created by the arrangement of intersecting myocardial fibers (at the juncture points of both the LV and RV) and therefore accumulation of gadolinium in this area is unlikely to represent replacement fibrosis.

With current CMR technology it is not possible to reliably distinguish interstitial (matrix) from replacement fibrosis, or an expanded matrix compartment created by myocyte disarray [100]. This may be an important limitation to contrast-CMR, as these forms of histopathology in HCM may portend different clinical consequences, particularly regarding susceptibility to potentially life-threatening arrhythmias.
Nevertheless, there has been interest in using CMR to differentiate myocardial substrates of different histologic composition. This principle has been addressed predominantly in patients with atherosclerotic coronary artery disease and prior myocardial infarction, in which areas of intermediate LGE signal intensity (ie., "grey-zone") correlate histologically to regions of "tissue heterogeneity' (mixture of isolated myocytes and fibrosis), while regions of higher signal intensity LGE correlate with core infarct zones comprised of only replacement scar [105]. Identification of areas of tissue heterogeneity are of potential importance, as these regions may represent a more arrthymogenic substrate than the core infarct [106].

In HCM, areas of lesser signal intensity LGE are also common but have largely been ignored in prior analysis of hyperenhancement in this disease and therefore their potential for generating life-threatening ventricular arrhythmias largely ignored [37-39,89,93]. However, a recent investigation in $\mathrm{HCM}$, applying a similar imaging strategy to that used in ischemic cardiomyopathy to identify the "grey zone" border surrounding core infarct, demonstrated that magnitude of intermediate LGE signal intensity ( $\geq 4$ but $<6$ SD above the mean SI of nulled myocardium) was a more reliable LGE discriminator for identifying HCM patients with ambulatory complex arrhythmias such as NSVT than high signal intensity LGE ( $\geq 6$ SD) [107]. These data underscore the potential value in assessing regions of intermediate signal intensity LGE, which may identify another abnormal myocardial substrate more prone to ventricular tachyarrhythmias. In order to resolve this issue, further longitudinal studies are necessary to assess whether the character of LGE (intermediate vs. higher signal intensity) is a predictor of clinical outcome in HCM patients with preserved systolic function.

\section{Quantification of LGE in HCM}

Over the last several years, numerous techniques have been proposed to assess extent of LGE in HCM reflecting the uncertainty which persists regarding the most appropriate strategy for assessing hyperenhancement in this disease [108-112]. The most widely used techniques have been a variety of semi-automated algorithms which identify high signal intensity LGE pixels after applying a grayscale threshold a number of standard deviations (SD) above the mean signal intensity within a remote region of interest (ROI) containing normal "nulled" myocardium (i.e. 2, 4, 5 or 6 [SD])(Figure 9a) or peak intensity of scarred myocardium (i.e. full width at half maximum [FWHM]). In addition, the Raleigh curve method is a novel quantitative technique which addresses limitations inherent in defining a ROI (ie., the assumption that within an ROI the signal intensity pixels always conform to a Gaussian distribution) by 


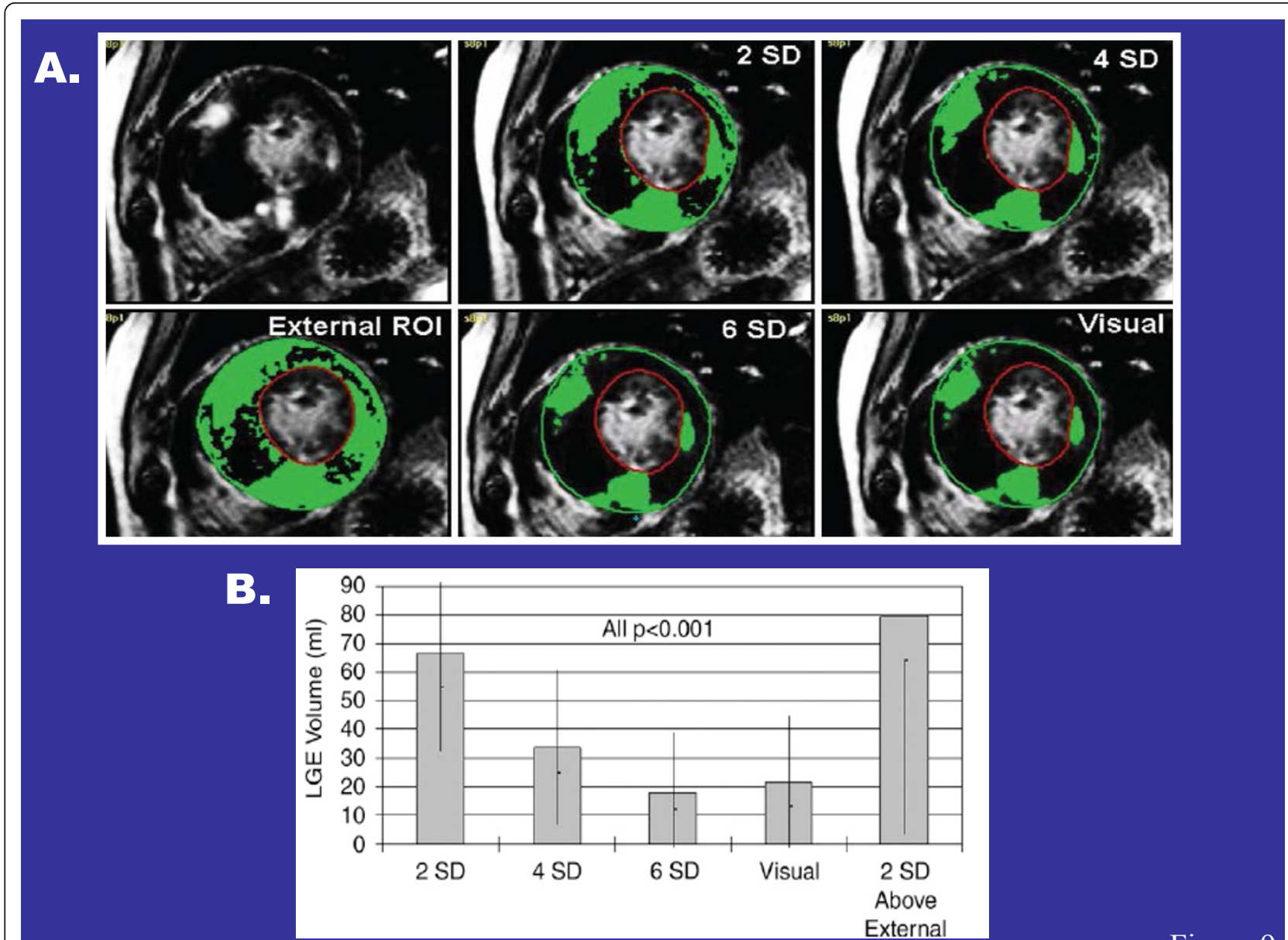

Figure 9 Quantification of LGE. (A) Identical LV short-axis contrast-enhanced cardiovascular MR images show LGE depicted with gray-scale thresholding techniques at 2, 4, and 6 SDs above mean signal intensity of normal remote myocardium, with visual assessment, and with 2 SDs above mean of external region of interest (ROI). LV endocardium and epicardium are outlined in red and green, respectively. Solid black areas in LV myocardium represent areas of delayed enhancement at corresponding semiautomated threshold; (B) Graph illustrates volumes of delayed enhancement (horizontal axis values) assessed by using various gray-scale thresholding techniques (2, 4, and 6 SDs above mean), visual assessment, and an external region of interest. Reproduced with permission, from Harrigan C et al.[113]

placing an ROI in the background of the image to generate a more ideal myocardial signal intensity distribution curve [108].

These thresholding algorithms has been most extensively studied in patients with ischemic cardiomyopathy, where grayscale techniques using $2 \mathrm{SD}$ above the mean of normal myocardial SI or FWHM have been shown to correlate well with the spatial extent of the infarct $[101,113]$. In addition, because the infarct scar is surrounded by an otherwise structurally normal myocardium there are no significant differences in the amount of LGE if a 2SD threshold is applied compared to using other grayscale thresholds.

However, HCM represents a distinctly different disease entity in which abnormal myocardial substrate (interstitial-matrix, replacement fibrosis and areas of myocyte disarray) involve large proportions of LV myocardium [106,114-116]. Therefore, directly extrapolating fundamental principles of LGE analysis from patients following CAD-related myocardial infarction to those with HCM may incorporate flawed assumptions [111]. For example, in an individual HCM patient there may be significant differences in amount of LGE identified depending on which greyscale threshold technique is chosen, with a $2 \mathrm{SD}$ threshold resulting in a 2 -fold greater amount of hyperenhancement compared to a 6SD threshold (Figure 9B) [108,111,112]. However, 6 SD and FWHM have been found to most closely approximate the extent of fibrosis compared with visual assessment (or the Raleigh curve method) and to be the most reproducible method for quantification of LGE in HCM compared to other grayscale thresholds (Figure 9b) $[108,111,112]$. Therefore, in the absence of data comparing LGE images to that of ex vivo histopathology in an 
HCM patient with preserved EF (or appropriate animal models), it seems most reasonable at this time to promote the use of either of these two methods for quantifying LGE in HCM.

Furthermore, there are a number of technical issues to consider as potential limitations with respect to LGE images. The quality of contrast-enhanced images can be affected by the selection of poor inversion times and motion artifact, making it difficult to reliably determine in such cases whether LGE represents abnormal histopathology versus "background noise" [117]. In addition, a number of different types of sequences are now being used to acquire LGE images, including 3-D segmented inversion-recovery, phase-sensitive inversion-recovery and equilibrium contrast CMR [117-119]. There are currently no data available which compare the extent of LGE identified using these different techniques, and there is variability among individual operators with respect to optimizing respective image parameters. The limitations with respect to quantification of LGE in HCM is underscored by the fact that the 4 short-term follow-up contrast-enhanced CMR studies in this disease have each applied a different quantification method to determine the presence and/or extent of LGE, which provides an additional explanation for why the results of these outcome studies are so dissimilar [36-39].

At present, the totality of these data suggests a note of caution is appropriate in interpreting the significance of LGE from a histologic perspective in patients with HCM. It is reasonable to conclude that in end-stage HCM patients the majority of LGE represents myocardial replacement fibrosis responsible for the adverse LV remodeling evident. It remains less clear to what extent LGE equates to scar formation among the more typical HCM patients with preserved EF, who comprise the vast majority of patients with this disease. Nevertheless, even if all hyperenhancement does not equate with fibrosis, LGE may still prove to be an important clinical marker for prognosis in this disease. In addition, at this early juncture, there still remains a great need for standardization of LGE quantification methods and sequence acquisition, given that the substantial amount of variability evident among these techniques represents a potential limitation in applying CMR to routine clinical decision-making.

\section{Conclusions}

Over the last decade, the unique imaging strengths of CMR have led to improved diagnostic capabilities and expanded our understanding and appreciation of the diverse phenotypic expression of this complex genetic heart disease. In addition, CMR has an emerging role in the assessment of risk in patients with HCM, as substantially increased LV mass and late gadolinium enhancement have been associated with increased likelihood of future adverse cardiovascular events. Taken together, these observations underscore an important and growing role for CMR in the contemporary evaluation of HCM patients and support the need for future longitudinal studies to clarify whether CMR-derived variables will be independent predictors of sudden death and disease progression.

\section{List of Abbreviations}

CMR: cardiovascular magnetic resonance; EF: ejection fraction; HCM: hypertrophic cardiomyopathy; ICD: implantable cardioverter defibrillator; LGE: late gadolinium enhancement; LV: left ventricle; RV: right ventricle; SAM: systolic anterior motion

\section{Acknowledgements}

None

\section{Authors' contributions}

I have read and approved the manuscript

\section{Authors Information}

Dr. Martin Maron is an assistant professor of medicine and Director of the Hypertrophic Cardiomyopathy Center and Co-Director of Advanced Cardiac Imaging at Tufts Medical Center. His research interests involve the role of cardiovascular magnetic resonance (CMR) in the evaluation and management of patients with $\mathrm{HCM}$ as well as investigating novel drug therapy to modify the HCM phenotype. Dr. Maron also collaborates with members of the Molecular Cardiology Research Institute (MCRI) at Tufts on several projects aimed at better characterizing the molecular pathways which contribute to disease expression in HCM. Several of these on-going projects include evaluating the relationship of novel polymorphisms with regard to the expression of hypertrophy and characterizing signaling pathways which promote the upregulation of cardiac fibroblasts and their promotion of adverse remodeling in HCM.

\section{Competing interests}

Consultant PGx Health

Received: 22 December 2011 Accepted: 1 February 2012

Published: 1 February 2012

\section{References}

1. Maron BJ: Hypertrophic cardiomyopathy: a systematic review. JAMA 2002, 287:1308-20.

2. Wigle ED, Rakowski H, Kimball BP, Williams WG: Hypertrophic cardiomyopathy. Clinical spectrum and treatment. Circulation 1995, 92:1680-92.

3. Maron BJ, McKenna WJ, Danielson GK, Kappenberger $L$, Kuhn HJ, Seidman CE, Shah PM, Spencer WH, Spirito P, Ten Cate FJ, Wigle ED: American College of Cardiology/European Society of Cardiology clinical expert consensus document on hypertrophic cardiomyopathy. A report of the American College of Cardiology Foundation Task Force on Clinical Expert Consensus Documents and the European Society of Cardiology Committee for Practice Guidelines. J Am Coll Cardiol 2003, 42:1687-713.

4. Alcalai R, Seidman JG, Seidman CE: Genetic basis of hypertrophic cardiomyopathy: from bench to the clinics. J Cardiovasc Electrophysiol 2008, 19:104-10

5. Seidman JG, Seidman C: The genetic basis for cardiomyopathy: from mutation identification to mechanistic paradigms. Cell 2001, 104:557-67.

6. Wigle ED, Sasson Z, Henderson MA, Ruddy TD, Fulop J, Rakowski H, Williams WG, Hypertrophic cardiomyopathy: The importance of the site and the extent of hypertrophy. A review. Prog Cardiovasc Dis 1985, 28:1-83.

7. Maron BJ: Hypertrophic cardiomyopathy: an important global disease. Am J Med 2004, 116:63-5. 
8. Olivotto I, Maron MS, Adabag AS, Casey SA, Vargiu D, Link MS, Udelson JE, Cecchi F, Maron BJ: Gender-related differences in the clinical presentation and outcome of hypertrophic cardiomyopathy. J Am Coll Cardiol 2005, 46:480-7

9. Cecchi F, Olivotto I, Montereggi A, Santoro G, Dolara A, Maron BJ: Hypertrophic cardiomyopathy in Tuscany: clinical course and outcome in an unselected regional population. J Am Coll Cardiol 1995, 26:1529-36

10. Maron BJ, Casey SA, Hauser RG, Aeppli DM: Clinical course of hypertrophic cardiomyopathy with survival to advanced age. J Am Coll Cardiol 2003, 42:882-8.

11. Maron BJ, Casey SA, Poliac LC, Gohman TE, Almquist AK, Aeppli DM: Clinical course of hypertrophic cardiomyopathy in a regional United States cohort. JAMA 1999, 281:650-5.

12. Elliott PM, Poloniecki J, Dickie S, Sharma S, Monserrat L, Varnava A, Mahon NG, McKenna WJ: Sudden death in hypertrophic cardiomyopathy: identification of high risk patients. J Am Coll Cardiol 2000, 36:2212-8.

13. Maron BJ, Olivotto I, Spirito P, Casey SA, Bellone P, Gohman TE, Graham KJ, Burton DA, Cecchi F: Epidemiology of hypertrophic cardiomyopathyrelated death: revisited in a large non-referral-based patient population. Circulation 2000, 102:858-64.

14. Melacini P, Basso C, Angelini A, Calore C, Bobbo F, Tokajuk B, Bellini N, Smaniotto G, Zuachetto M, lliceto S, Thiene G, Maron BJ: Clinicopathological profiles of progressive heart failure in hypertrophic cardiomyopathy. Eur Heart J 2010, 31:2111-23.

15. Olivotto I, Cecchi F, Casey SA, Dolara A, Traverse JH, Maron BJ: Impact of atrial fibrillation on the clinical course of hypertrophic cardiomyopathy. Circulation 2001, 104:2517-24

16. Ackerman MJ, VanDriest SL, Ommen SR, Will ML, Nishimura RA, Tajik AJ, Gersh BJ: Prevalence and age-dependence of malignant mutations in the beta-myosin heavy chain and troponin $T$ genes in hypertrophic cardiomyopathy: a comprehensive outpatient perspective. J Am Coll Cardiol 2002, 39:2042-8.

17. Ho CY: Genetics and clinical destiny: improving care in hypertrophic cardiomyopathy. Circulation 2010, 122:2430-40.

18. Watkins H, Thierfelder L, Hwang DS, McKenna W, Seidman JG, Seidman CE: Sporadic hypertrophic cardiomyopathy due to de novo myosin mutations. J Clin Invest 1992, 90:1666-71.

19. Maron BJ, Niimura H, Casey SA, Soper MK, Wright GB, Seidman JG Seidman CE: Development of left ventricular hypertrophy in adults in hypertrophic cardiomyopathy caused by cardiac myosin-binding protein C gene mutations. J Am Coll Cardiol 2001, 38:315-21.

20. Wheeler M, Pavlovic A, DeGoma E, Salisbury H, Brown C, Ashley EA: A new era in clinical genetic testing for hypertrophic cardiomyopathy. $J$ Cardiovasc Transl Res 2009, 2:381-91.

21. Bos JM, Towbin JA, Ackerman MJ: Diagnostic, prognostic, and therapeutic implications of genetic testing for hypertrophic cardiomyopathy:. J Am Coll Cardiol 2009, 54:201-11.

22. Watkins H, Rosenzweig A, Hwang DS, Levi T, McKenna W, Seidman CE, Seidman JG: Characteristics and prognostic implications of myosin missense mutations in familial hypertrophic cardiomyopathy. N Engl J Med 1992, 326:1108-14.

23. Maron BJ, Yeates L, Semsarian C: Clinical Challenges of Genotype Positive (+)-Phenotype Negative (-) Family Members in Hypertrophic Cardiomyopathy. Am J Cardiol 2010.

24. Maron BJ, Roberts WC, Arad M, Haas TS, Spirito P, Wright GB, Almquist AK, Baffa JM, Saul JP, Ho CY, Seidman JG, Seidman CE: Clinical outcome and phenotypic expression in LAMP2 cardiomyopathy. JAMA 2009, 301:1253-9.

25. Van Driest SL, Ackerman MJ, Ommen SR, Shakur R, Will ML, Nishimura RA Tajik AJ, Gersh BJ: Prevalence and severity of "benign" mutations in the beta-myosin heavy chain, cardiac troponin $\mathrm{T}$, and alpha-tropomyosin genes in hypertrophic cardiomyopathy. Circulation 2002, 106:3085-90.

26. Maron BJ: Contemporary insights and strategies for risk stratification and prevention of sudden death in hypertrophic cardiomyopathy. Circulation 2010, 121:445-56.

27. Binder J, Ommen SR, Gersh BJ, Van Driest SL, Tajik AJ, Nishimura RA, Ackerman MJ: Echocardiography-guided genetic testing in hypertrophic cardiomyopathy: septal morphological features predict the presence of myofilament mutations. Mayo Clinic proceedings 2006, 81:459-67.

28. Kramer CM: The expanding prognostic role of late gadolinium enhanced cardiac magnetic resonance. J Am Coll Cardiol 2006, 48:1986-7.
29. Maron MS, Maron BJ, Harrigan C, Buros J, Gibson CM, Olivotto I, Biller L, Lesser JR, Udelson JE, Manning WJ, Appelbaum E: Hypertrophic cardiomyopathy phenotype revisited after 50 years with cardiovascular magnetic resonance. J Am Coll Cardiol 2009, 54:220-8.

30. Pennell DJ: Cardiovascular magnetic resonance. Circulation 2010, 121:692-705

31. Reichek N, Gupta D: Hypertrophic cardiomyopathy: cardiac magnetic resonance imaging changes the paradigm. J Am Coll Cardiol 2008, 52:567-8.

32. Rochitte CE, Tassi EM, Shiozaki AA: The emerging role of MRI in the diagnosis and management of cardiomyopathies. Curr Cardiol Rep 2006, 8:44-52.

33. Moon JC, McKenna WJ: The emerging role of cardiovascular magnetic resonance in refining the diagnosis of hypertrophic cardiomyopathy. Nat Clin Pract Cardiovasc Med 2009, 6:166-7

34. O'Hanlon R, Assomull RG, Prasad SK: Use of cardiovascular magnetic resonance for diagnosis and management in hypertrophic cardiomyopathy. Curr Cardiol Rep 2007, 9:51-6.

35. Rickers C, Wilke NM, Jerosch-Herold M, Casey SA, Panse P, Panse N, Weil J, Zenovich AG, Maron BJ: Utility of cardiac magnetic resonance imaging in the diagnosis of hypertrophic cardiomyopathy. Circulation 2005, 112:855-61.

36. Bruder O, Wagner A, Jensen CJ, Schneider S, Ong P, Kispert EM, Nassenstein K, Sahlosser T, Sabin GV, Sechtem U, Marholdt H: Myocardial scar visualized by cardiovascular magnetic resonance imaging predicts major adverse events in patients with hypertrophic cardiomyopathy. $J$ Am Coll Cardiol 2010, 56:875-87.

37. Maron MS, Appelbaum E, Harrigan CJ, Buros J, Gibson CM, Hanna C, Lesser JR, Udelson JE, Manning WJ, Maron BJ: Clinical profile and significance of delayed enhancement in hypertrophic cardiomyopathy. Circ Heart Fail 2008, 1:184-91.

38. O'Hanlon R, Grasso A, Roughton M, Moon JC, Clark S, Wage R, Webb J, Kulkarni M, Dawson D, Sulaibeekh L, Chandrasekaran B, Bucciaselli-Ducci C, Pasquale F, Cowie MR, McKenna WJ, Sheppard MN, Elliott PM, Pennell DJ: Prognostic significance of myocardial fibrosis in hypertrophic cardiomyopathy. J Am Coll Cardiol 2010, 56:867-74.

39. Rubinshtein R, Glockner JF, Ommen SR, Araoz PA, Ackerman MJ, Sorajja P, Bos JM, Tajik AJ, Valeti US, Nishimura RA, Gersh BJ: Characteristics and clinical significance of late gadolinium enhancement by contrastenhanced magnetic resonance imaging in patients with hypertrophic cardiomyopathy. Circ Heart Fail 2010, 3:51-8.

40. Klues HG, Schiffers A, Maron BJ: Phenotypic spectrum and patterns of left ventricular hypertrophy in hypertrophic cardiomyopathy: morphologic observations and significance as assessed by two-dimensional echocardiography in 600 patients. J Am Coll Cardiol 1995, 26:1699-708.

41. Nagueh SF, Bierig SM, Budoff MJ, Desai M, Dilsizian V, Eidem B, Goldstein S, Hung J, Maron MS, Ommen SR, Woo A: American Society of Echocardiography clinical recommendations for multimodality cardiovascular imaging of patients with hypertrophic cardiomyopathy: Endorsed by the American Society of Nuclear Cardiology, Society for Cardiovascular Magnetic Resonance, and Society of Cardiovascular Computed Tomography. J Am Soc Echocardiogr 2011, 24:473-98.

42. Maron MS, Lesser JR, Maron BJ: Management implications of massive left ventricular hypertrophy in hypertrophic cardiomyopathy significantly underestimated by echocardiography but identified by cardiovascular magnetic resonance. Am J Cardiol 2010, 105:1842-3.

43. Moon JC, Fisher NG, McKenna WJ, Pennell DJ: Detection of apical hypertrophic cardiomyopathy by cardiovascular magnetic resonance in patients with non-diagnostic echocardiography. Heart 2004, 90:645-9.

44. Fattori R, Biagini E, Lorenzini M, Buttazzi K, Lovato L, Rapezzi C: Significance of magnetic resonance imaging in apical hypertrophic cardiomyopathy. Am J Cardiol 2010, 105:1592-6.

45. Ates M, Kwong RY, Lipton MJ, Tatli S: Apical hypertrophic cardiomyopathy: diagnosed by cardiac magnetic resonance imaging. Tex Heart Inst J 2006, 33:408-9.

46. Olivotto I, Maron MS, Autore C, Lesser JR, Rega L, Casolo G, De Santi M, Quarta G, Nistri S, Cecchi F, Salton CJ, Udelson JE, Manning WJ, Maron BJ: Assessment and significance of left ventricular mass by cardiovascular magnetic resonance in hypertrophic cardiomyopathy. J Am Coll Cardiol 2008, 52:559-66. 
47. Maron MS, Hauser TH, Dubrow E, Horst TA, Kissinger KV, Udelson JE, Manning WJ: Right ventricular involvement in hypertrophic cardiomyopathy. Am J Cardiol 2007, 100:1293-8.

48. Keeling AN, Carr JC, Choudhury L: Right ventricular hypertrophy and scarring in mutation positive hypertrophic cardiomyopathy. European heart journal 2010, 31:381.

49. Holloway CJ, Betts TR, Neubauer S, Myerson SG: Hypertrophic cardiomyopathy complicated by large apical aneurysm and thrombus, presenting as ventricular tachycardia. J Am Coll Cardiol 2010, 56:1961.

50. Maron MS, Finley JJ, Bos JM, Hauser TH, Manning WJ, Haas TS, Lesser JR, Udelson JE, Ackerman MJ, Maron BJ: Prevalence, clinical significance, and natural history of left ventricular apical aneurysms in hypertrophic cardiomyopathy. Circulation 2008, 118:1541-9.

51. Shenoy C, Maron MS: Hypertrophic cardiomyopathy with left ventricular apical aneurysm in brothers. Am J Cardiol 2011, 108:612-3.

52. Lim KK, Maron BJ, Knight BP: Successful catheter ablation of hemodynamically unstable monomorphic ventricular tachycardia in a patient with hypertrophic cardiomyopathy and apical aneurysm. J Cardiovasc Electrophysiol 2009, 20:445-7.

53. Maron MS, Olivotto I, Harrigan C, Appelbaum E, Gibson CM, Lesser JR, Haas TS, Udelson JE, Manning WJ, Maron BJ: Mitral valve abnormalities identified by cardiovascular magnetic resonance represent a primary phenotypic expression of hypertrophic cardiomyopathy. Circulation 2011, 124:40-7.

54. Harrigan CJ, Appelbaum E, Maron BJ, Buros JL, Gibson CM, Lesser JR, Udelson JE, Manning WJ, Maron BJ: Significance of papillary muscle abnormalities identified by cardiovascular magnetic resonance in hypertrophic cardiomyopathy. Am J Cardiol 2008, 101:668-73.

55. Kwon DH, Setser RM, Thamilarasan M, Popovic ZV, Smedira NG, Schoenhagen P, Garcia MJ, Lever HM, Desai MY: Abnormal papillary muscle morphology is independently associated with increased left ventricular outflow tract obstruction in hypertrophic cardiomyopathy. Heart 2008, 94:1295-301.

56. Germans T, Wilde AA, Dijkmans PA, Chai W, Kamp O, Pinto YM, van Rossum AC: Structural abnormalities of the inferoseptal left ventricular wall detected by cardiac magnetic resonance imaging in carriers of hypertrophic cardiomyopathy mutations. J Am Coll Cardiol 2006, 48:2518-23.

57. Maron MS RE, Lin D, Applebaum E, Gibson CM, Lesser JR, Lindberg J, Haas TS, Udelson JE, Manning WJ, Maron BJ: Prevalence, Clinical Profile and Prognostic Significance of Myocardial Crypts in Hypertrophic Cardiomyopathy. J Am Col Cardiol 2011, 57:e191.

58. Rowin EJ, Maron MS, Lesser JR, Maron BJ: Cardiovascular Magnetic Resonance Imaging in a Genotype Positive-Phenotype Negative Hypertrophic Cardiomyopathy Patient. JACC Cardiovasc Imaging 2012, 5:119-122.

59. Strijack B, Ariyarajah V, Soni R, Jassal DS, Greenberg CR, McGregor R, Morris A: Late gadolinium enhancement cardiovascular magnetic resonance in genotyped hypertrophic cardiomyopathy with normal phenotype. J Cardiovasc Magn Reson 2008, 10:58.

60. Ariyarajah $\mathrm{V}$, Tam JW, Khadem A: Inducible malignant ventricular tachyarrhythmia in a patient with genotyped hypertrophic cardiomyopathy in absence of left ventricular hypertrophy or enlargement. Circulation 2009, 119:e543-4.

61. Desai MY, Ommen SR, McKenna WJ, Lever HM, Elliott PM: Imaging phenotype versus genotype in hypertrophic cardiomyopathy. Circ Cardiovasc Imaging 2011, 4:156-68.

62. Arad M, Maron BJ, Gorham JM, Johnson WH Jr, Saul JP, Perez-Atayde AR, Spirito P, Wright GB, Kanter RJ, Seidman CE, Seidman JG: Glycogen storage diseases presenting as hypertrophic cardiomyopathy. N Engl J Med 2005, 352:362-72.

63. Maceira AM, Joshi J, Prasad SK, Moon JC, Perugini E, Harding I, Sheppard MN, Poole-Wilson PA, Hawkins PN, Pennell DJ: Cardiovascular magnetic resonance in cardiac amyloidosis. Circulation 2005, 111:186-93.

64. Gange CA, Link MS, Maron MS: Utility of cardiovascular magnetic resonance in the diagnosis of Anderson-Fabry disease. Circulation 2009, 120:e96-7.

65. Kelley-Hedgepeth A, Towbin JA, Maron MS: Overlapping phenotypes: left ventricular noncompaction and hypertrophic cardiomyopathy. Circulation 2009, 119:e588-9.
66. Spirito $P$, Autore C: Apical hypertrophic cardiomyopathy or left ventricular non-compaction? A difficult differential diagnosis. Eur Heart J 2007, 28:1923-4

67. Maron BJ: Distinguishing hypertrophic cardiomyopathy from athlete's heart physiological remodelling: clinical significance, diagnostic strategies and implications for preparticipation screening. British journal of sports medicine 2009, 43:649-56.

68. O'Hanlon R, Wilson M, Wage R, Smith G, Alpendurada FD, Wong J, Dahl A, Oxborough D, Godfrey R, Sharma S, Roughton M, George K, Pennell DJ, Whyte G, Prasad SK: Troponin release following endurance exercise: is inflammation the cause? a cardiovascular magnetic resonance study. J Cardiovasc Magn Reson 2010, 12:38.

69. Schulz-Menger J, Abdel-Aty H, Busjahn A, Wassmuth R, Pilz B, Dietz R, Friedrich MG: Left ventricular outflow tract planimetry by cardiovascular magnetic resonance differentiates obstructive from non-obstructive hypertrophic cardiomyopathy. J Cardiovasc Magn Reson 2006, 8:741-6.

70. Nishimura RA, Holmes DR Jr: Clinical practice. Hypertrophic obstructive cardiomyopathy. N Engl J Med 2004, 350:1320-7.

71. Ommen SR, Maron BJ, Olivotto I, Maron MS, Cecchi F, Betocchi S, Gersh BJ, Ackerman MJ, McCully RB, Dearani JA, Schaff HV, Danielson GK, Tajik AJ, Nishimura RA: Long-term effects of surgical septal myectomy on survival in patients with obstructive hypertrophic cardiomyopathy. J Am Coll Cardiol 2005, 46:470-6.

72. Sado DM, Flett AS, McGregor CG, Pantazis AA, Elliott PM, Moon JC: Myectomy plus Alfieri technique for outflow tract obstruction in hypertrophic cardiomyopathy. Circulation 2010, 122:938-9.

73. van der Lee C, ten Cate FJ, Geleijnse ML, Kofflard MJ, Pedone C, van Herwerden LA, Biagini E, Vletter WB, Serruys PW: Percutaneous versus surgical treatment for patients with hypertrophic obstructive cardiomyopathy and enlarged anterior mitral valve leaflets. Circulation 2005, 112:482-8.

74. Minakata K, Dearani JA, Nishimura RA, Maron BJ, Danielson GK: Extended septal myectomy for hypertrophic obstructive cardiomyopathy with anomalous mitral papillary muscles or chordae. J Thorac Cardiovasc Surg 2004, 127:481-9.

75. Agarwal S, Tuzcu EM, Desai MY, Smedira N, Lever HM, Lytle BW, Kapadia SR: Updated meta-analysis of septal alcohol ablation versus myectomy for hypertrophic cardiomyopathy. J Am Coll Cardiol 2010, 55:823-34.

76. Valeti US, Nishimura RA, Holmes DR, Araoz PA, Glockner JF, Breen JF, Ommen SR, Gersh BJ, Tajik AJ, Rihal CS, Schaff HV, Maron BJ: Comparison of surgical septal myectomy and alcohol septal ablation with cardiac magnetic resonance imaging in patients with hypertrophic obstructive cardiomyopathy. J Am Coll Cardiol 2007, 49:350-7.

77. Yuan J, Qiao S, Zhang Y, You S, Duan F, Hu F, Yang W: Follow-up by cardiac magnetic resonance imaging in patients with hypertrophic cardiomyopathy who underwent percutaneous ventricular septal ablation. Am J Cardiol 2010, 106:1487-91.

78. Spirito P, Bellone P, Harris KM, Bernabo P, Bruzzi P, Maron BJ: Magnitude of left ventricular hypertrophy and risk of sudden death in hypertrophic cardiomyopathy. N Engl J Med 2000, 342:1778-85.

79. Maron MS, Olivotto I, Maron BJ, Prasad SK, Cecchi F, Udelson JE, Maron BJ: The case for myocardial ischemia in hypertrophic cardiomyopathy. J Am Coll Cardiol 2009, 54:866-75.

80. Knaapen P, van Dockum WG, Gotte MJ, Broeze KA, Kuijer JP, Zwanenburg JJ: Regional heterogeneity of resting perfusion in hypertrophic cardiomyopathy is related to delayed contrast enhancement but not to systolic function: a PET and MRI study. J Nucl Cardiol 2006, 13:660-7.

81. Sotgia B, Sciagra R, Olivotto I, Casolo G, Rega L, Betti I, Pupi A, Camici PG, Cecchi F: Spatial relationship between coronary microvascular dysfunction and delayed contrast enhancement in patients with hypertrophic cardiomyopathy. J Nucl Med 2008, 49:1090-6.

82. Kwon DH, Smedira NG, Rodriguez ER, Tan C, Setser R, Thamilarasan M, Lytle BW, Lever HM: Cardiac magnetic resonance detection of myocardial scarring in hypertrophic cardiomyopathy: correlation with histopathology and prevalence of ventricular tachycardia. J Am Coll Cardiol 2009, 54:242-9

83. Olivotto I, Cecchi F, Gistri R, Lorenzoni R, Chiriatti G, Girolami F, Torricelli F, Camici PG: Relevance of coronary microvascular flow impairment to long-term remodeling and systolic dysfunction in hypertrophic cardiomyopathy. J Am Coll Cardiol 2006, 47:1043-8. 
84. Harris KM, Spirito P, Maron MS, Zenovich AG, Formisano F, Lesser JR Mackey-Bojack S, Manning WJ, Udelson JE, Maron BJ: Prevalence, clinical profile, and significance of left ventricular remodeling in the end-stage phase of hypertrophic cardiomyopathy. Circulation 2006, 114:216-25.

85. Moon JC, Reed E, Sheppard MN, Elkington AG, Ho SY, Burke M, Petrou M, Pennell DJ: The histologic basis of late gadolinium enhancement cardiovascular magnetic resonance in hypertrophic cardiomyopathy. J Am Coll Cardiol 2004, 43:2260-4.

86. Papavassiliu T, Schnabel $P$, Schroder $M$, Borggrefe M: CMR scarring in a patient with hypertrophic cardiomyopathy correlates well with histological findings of fibrosis. European heart journal 2005, 26:2395.

87. Moon JC, McKenna WJ, McCrohon JA, Elliott PM, Smith GC, Pennell DJ: Toward clinical risk assessment in hypertrophic cardiomyopathy with gadolinium cardiovascular magnetic resonance. J Am Coll Cardiol 2003, 41:1561-7.

88. Choudhury L, Mahrholdt H, Wagner A, Choi KM, Elliott MD, Klocke FJ, Bonow RO, Judd RM, Kim RJ: Myocardial scarring in asymptomatic or mildly symptomatic patients with hypertrophic cardiomyopathy. J Am Coll Cardiol 2002, 40:2156-64.

89. Olivotto I, Maron BJ, Appelbaum E, Harrigan CJ, Salton C, Gibson CM, Udelson JE, O'Donnell C, Lesser JR, Manning WJ, Maron MS: Spectrum and clinical significance of systolic function and myocardial fibrosis assessed by cardiovascular magnetic resonance in hypertrophic cardiomyopathy. Am J Cardiol 2010, 106:261-7

90. Maron MS, Olivotto I, Betocchi S, Casey SA, Lesser JR, Losi MA, Cecchi F, Maron BJ: Effect of left ventricular outflow tract obstruction on clinical outcome in hypertrophic cardiomyopathy. N Engl J Med 2003, 348:295-303.

91. Maron BJ, Maron MS, Lesser JR, Hauser RG, Haas TS, Harrigan CJ, Appelbaum E, Main ML, Roberts WC: Sudden cardiac arrest in hypertrophic cardiomyopathy in the absence of conventional criteria for high risk status. Am J Cardiol 2008, 101:544-7.

92. Bongioanni S, Spirito P, Masi AS, Chiribiri A, Bonamini R, Conte MR: Extensive myocardial fibrosis in a patient with hypertrophic cardiomyopathy and ventricular tachycardia without traditional high-risk features. Circ Cardiovasc Imaging 2009, 2:349-50.

93. Adabag AS, Maron BJ, Appelbaum E, Harrigan CJ, Buros JL, Gibson CM, Lesser JR, Hanna CA, Udelson JE, Manning WJ, Maron MS: Occurrence and frequency of arrhythmias in hypertrophic cardiomyopathy in relation to delayed enhancement on cardiovascular magnetic resonance. J Am Coll Cardiol 2008, 51:1369-74.

94. Fluechter S, Kuschyk J, Wolpert C, Doesch C, Veltmann C, Haghi D, Schoenberg SO, Sueselbeck T, Germans T, Streitner F, Borggrefe M, Papavassiliu T: Extent of late gadolinium enhancement detected by cardiovascular magnetic resonance correlates with the inducibility of ventricular tachyarrhythmia in hypertrophic cardiomyopathy. J Cardiovasc Magn Reson 2010, 12:30.

95. Kwon DH, Setser RM, Popovic ZB, Thamilarasan M, Sola S, Schoenhagen P, Garcia MJ, Flamm SD, Lever HM: Association of myocardial fibrosis, electrocardiography and ventricular tachyarrhythmia in hypertrophic cardiomyopathy: a delayed contrast enhanced MRI study. Int J Cardiovasc Imaging 2008, 24:617-25.

96. Suk T, Edwards C, Hart H, Christiansen JP: Myocardial scar detected by contrast-enhanced cardiac magnetic resonance imaging is associated with ventricular tachycardia in hypertrophic cardiomyopathy patients. Heart Lung Circ 2008, 17:370-4.

97. Aquaro GD, Masci P, Formisano F, Barison A, Strata E, Pingitore A, Positano V, Spirito P, Lombardi M: Usefulness of delayed enhancement by magnetic resonance imaging in hypertrophic cardiomyopathy as a marker of disease and its severity. Am J Cardiol 2010, 105:392-7.

98. Monserrat L, Elliott PM, Gimeno JR, Sharma S, Penas-Lado M, McKenna WJ: Non-sustained ventricular tachycardia in hypertrophic cardiomyopathy: an independent marker of sudden death risk in young patients. J Am Coll Cardiol 2003, 42:873-9.

99. Salerno M, Kramer CM: Prognosis in hypertrophic cardiomyopathy with contrast-enhanced cardiac magnetic resonance: the future looks bright. J Am Coll Cardiol 2010, 56:888-9.

100. Kim RJ, Judd RM: Gadolinium-enhanced magnetic resonance imaging in hypertrophic cardiomyopathy: in vivo imaging of the pathologic substrate for premature cardiac death? J Am Coll Cardiol 2003, 41:1568-72.
101. Kim RJ, Fieno DS, Parrish TB, Harris K, Chen EL, Simonetti O, Bundy J, Finn JP, Klocke FJ, Judd RM: Relationship of MRI delayed contrast enhancement to irreversible injury, infarct age, and contractile function. Circulation 1999, 100:1992-2002.

102. Petersen SE, Jerosch-Herold M, Hudsmith LE, Robson MD, Francis JM, Doll HA, Selvanayagam JB, Neubauer S, Watkins H: Evidence for microvascular dysfunction in hypertrophic cardiomyopathy: new insights from multiparametric magnetic resonance imaging. Circulation 2007, $115: 2418-25$

103. Kim RJ, Wu E, Rafael A, Chen EL, Parker MA, Simonetti O, Klocke FJ, Bonow RO, Judd RM: The use of contrast-enhanced magnetic resonance imaging to identify reversible myocardial dysfunction. The New England journal of medicine 2000, 343:1445-53.

104. Kuribayashi T, Roberts WC: Myocardial disarray at junction of ventricular septum and left and right ventricular free walls in hypertrophic cardiomyopathy. Am J Cardiol 1992, 70:1333-40.

105. Schmidt A, Azevedo CF, Cheng A, Gupta SN, Bluemke DA, Foo TK, Lima JA, Wu KC: Infarct tissue heterogeneity by magnetic resonance imaging identifies enhanced cardiac arrhythmia susceptibility in patients with left ventricular dysfunction. Circulation 2007, 115:2006-14.

106. Yan AT, Shayne AJ, Brown KA, Gupta SN, Chan CW, Luu TM, Di Carli MF, Reynolds HG, Stevenson WG, Kwong RY: Characterization of the periinfarct zone by contrast-enhanced cardiac magnetic resonance imaging is a powerful predictor of post-myocardial infarction mortality. Circulation 2006, 114:32-9.

107. Appelbaum EMB, Adabag S, Hauser TH, Lesser JR, Haas TS, Riley A, Harrigan CJ, Delling F, Udelson JE, Gibson CM, Manning WJ, Maron MS: Extent of Intermediate Signal Intensity Late Gadolinium Enhancement Predicts Ventricular Tachyarrythmias in Patients with Hypertrophic Cardiomyopathy. Circ Cardiovasc Imaging 2011.

108. Aquaro GD, Positano V, Pingitore A, Strata E, Di Bella G, Formisano F, Spirito P, Lombardi M: Quantitative analysis of late gadolinium enhancement in hypertrophic cardiomyopathy. J Cardiovasc Magn Reson 2010, 12:21.

109. Spiewak M, Malek LA, Misko J, Chojnowska L, Milosz B, Klopotowski M, Milosz B, Polanska M, Puzylio W: Comparison of different quantification methods of late gadolinium enhancement in patients with hypertrophic cardiomyopathy. Eur J Radiol 2010, 74:e149-53.

110. Tanaka M, Fujiwara H, Onodera T, Wu DJ, Hamashima Y, Kawai C: Quantitative analysis of myocardial fibrosis in normals, hypertensive hearts, and hypertrophic cardiomyopathy. Br Heart J 1986, 55:575-81.

111. Flett AS, Hasleton J, Cook C, Hausenloy D, Quarta G, Ariti C, Muthurangu V, Moon JC: Evaluation of techniques for the quantification of myocardial scar of differing etiology using cardiac magnetic resonance. JACC Cardiovascular imaging 2011, 4:150-6.

112. Harrigan CJ, Peters DC, Gibson CM, Maron BJ, Manning WJ, Maron MS, Appelbaum E: Hypertrophic cardiomyopathy: quantification of late gadolinium enhancement with contrast-enhanced cardiovascular MR imaging. Radiology 2011, 258:128-33.

113. Amado LC, Gerber BL, Gupta SN, Rettmann DW, Szarf G, Schock R, Nasir K, Kraitchman DC, Lima JA: Accurate and objective infarct sizing by contrast-enhanced magnetic resonance imaging in a canine myocardial infarction model. J Am Coll Cardiol 2004, 44:2383-9.

114. Basso C, Thiene G, Corrado D, Buja G, Melacini P, Nava A: Hypertrophic cardiomyopathy and sudden death in the young: pathologic evidence of myocardial ischemia. Hum Pathol 2000, 31:988-98.

115. Shirani J, Pick R, Roberts WC, Maron BJ: Morphology and significance of the left ventricular collagen network in young patients with hypertrophic cardiomyopathy and sudden cardiac death. J Am Coll Cardiol 2000, 35:36-44.

116. Varnava AM, Elliott PM, Sharma S, McKenna WJ, Davies MJ: Hypertrophic cardiomyopathy: the interrelation of disarray, fibrosis, and small vessel disease. Heart 2000, 84:476-82

117. Kim HW, Farzaneh-Far A, Kim RJ: Cardiovascular magnetic resonance in patients with myocardial infarction: current and emerging applications. J Am Coll Cardiol 2009, 55:1-16.

118. Flett AS, Hayward MP, Ashworth MT, Hansen MS, Taylor AM, Elliott PM, McGregor C, Moon JC: Equilibrium contrast cardiovascular magnetic resonance for the measurement of diffuse myocardial fibrosis: preliminary validation in humans. Circulation 2010, 122:138-44. 
119. Huber AM, Schoenberg SO, Hayes C, Spannagl B, Engelmann MG, Franz WM: Phase-sensitive inversion-recovery MR imaging in the detection of myocardial infarction. Radiology 2005, 237:854-60.

doi:10.1186/1532-429X-14-13

Cite this article as: Maron: Clinical Utility of Cardiovascular Magnetic Resonance in Hypertrophic Cardiomyopathy. Journal of Cardiovascular Magnetic Resonance 2012 14:13.

Submit your next manuscript to BioMed Central and take full advantage of:

- Convenient online submission

- Thorough peer review

- No space constraints or color figure charges

- Immediate publication on acceptance

- Inclusion in PubMed, CAS, Scopus and Google Scholar

- Research which is freely available for redistribution

Submit your manuscript at www.biomedcentral.com/submit 